Article

\title{
Micellization Behaviour of Linear and Nonlinear Block Copolymers Based on Poly(n-hexyl isocyanate) in Selective Solvents
}

\author{
Aggelos Vazaios, Athanasios Touris ${ }^{\circledR}$, Mikel Echeverria, Georgia Zorba and Marinos Pitsikalis * \\ Industrial Chemistry Laboratory, Department of Chemistry, National and Kapodistrian University of Athens, \\ Panepistimiopolis Zografou, 15771 Athens, Greece; aggelosvazaios@gmail.com (A.V.); \\ atouris31@gmail.com (A.T.); mechmug@gmail.com (M.E.); gzormpa@hotmail.com (G.Z.) \\ * Correspondence: pitsikalis@chem.uoa.gr; Tel.: +30-210-727-4440
}

Received: 29 June 2020; Accepted: 21 July 2020; Published: 28 July 2020

\begin{abstract}
Block copolymers have attracted significant scientific and economic interest over the last decades due to their ability to self-assemble into ordered structures both in bulk and in selective solvents. In this work, the self-assembly behaviour of both linear (diblocks, triblocks and pentablocks) and nonlinear (miktoarm stars and a block-graft) copolymers based on poly(n-hexyl isocyanate), PHIC, were studied in selective solvents such as n-heptane and n-dodecane. A variety of experimental techniques, namely static and dynamic light scattering, dilute solution viscometry and atomic force microscopy, were employed to study the micellar structural parameters (e.g., aggregation number, overall micellar size and shape, and core and shell dimensions). The effect of the macromolecular architecture, the molecular weight and the copolymer composition on the self-assembly behaviour was studied. Spherical micelles in equilibrium with clusters were obtained from the block copolymers. Thermally stable, uniform and spherical aggregates were found from the triblock copolymers. The poly(n-hexyl isocyanate)-b-polyisoprene-b-poly(n-hexyl isocyanate),-HIH copolymers tend to adopt closed loop conformation, leading to more elongated cylindrical-type structures upon increasing the concentration. Clustering effects were also reported in the case of the pentablock terpolymers. The topology of the blocks plays an important role, since the poly(n-hexyl isocyanate)-b-polystyrene-b-polyisoprene-b-polystyrene-b-poly(n-hexyl isocyanate), HSISH terpolymer shows intermicellar fusion of spherical micelles, leading to the formation of extended networks. The formation of spherical micelles in equilibrium with clusters was obvious in the case of the miktoarm stars, whereas the block-graft copolymer shows the existence of mainly unimolecular micelles.
\end{abstract}

Keywords: micelles; self-assembly; solution properties; polyisocyanates; rod-coil copolymers; light scattering; atomic force microscopy

\section{Introduction}

Block copolymers are without any doubt the most important class of polymeric materials [1,2]. This is due (a) to the numerous methodologies and techniques that are available for the synthesis of well-defined products with predetermined molecular characteristics and low molecular and chemical heterogeneity. A huge variety of structures with all kinds of combinations of polymeric chains, molecular weights and compositions has been synthesized over the years [3,4], (b) to their self-assembly behaviour as a result of the immiscibility of the constituent blocks. In bulk, this immiscibility results in microphase separation and the formation of long-range ordered nanostructures, such as spheres, cylinders, lamellae, bicontinuous structures, etc. [5,6]. In a selective solvent, which is a thermodynamically good solvent 
for the one block and non-solvent for the other block, the copolymers self-assemble, leading to the formation of supramolecular structures, called micelles [7-9], and (c) to their numerous and diverse applications, such as colloidal stabilization [10,11], latex technology [12], compatibilization in polymer blends [13], controlled drug delivery [14-17], water purification [18,19], viscosity and surface modification [20-23], catalytic supports [24], lithographic templates [25], nanoreactors [26,27], etc.

More recent advances in polymer chemistry have allowed the synthesis of nonlinear copolymer structures in a very controlled way [28-32]. Thus, star-block, miktoarm star, graft, and block-graft copolymers along with more complex macromolecular structures have been synthesized. From these studies, it became evident that the polymer properties and especially their self-assembly behaviour both in bulk and in selective solvents is significantly influenced by the macromolecular architecture [33-38].

In the past, a great effort was made by our group towards the synthesis of well-defined products based on poly(hexyl isocyanate), PHIC. PHIC chains are very stiff adopting dynamic helical structures both in bulk and in a wide range of solvents [39-42]. The reason for this behaviour is the resonance delocalization of the nitrogen and carbonyl electrons and the steric hindrance induced by the monomer's bulky side group. Thus, polyisocyanates possess an extended $8 / 3$ helical conformation instead of a restricted coplanar conformation [43]. Block copolymers with polystyrene (PS) and polyisoprene (PI) [44-46], triblock copolymers, pentablock terpolymers [47], graft copolymers, star polymers, star-block copolymers, miktoarm stars and block-graft copolymers [48-50] have been synthesized based either on anionic [51] or coordination polymerization of $n$-hexyl isocyanate, HIC employing half-Titanocene complexes [52-57]. Polyisocyanates have found tremendous applications in nanoscience and materials science as degradable and chiral recognition materials, optical switches, liquid crystals, etc. [58-63].

In this work, the micellization behaviour of certain PHIC-based polymers will be examined by a variety of experimental techniques, such as low-angle laser light scattering (LALLS), dynamic light scattering (DLS), dilute solution viscometry, along with atomic force microscopy (AFM). In particular, these structures involve PS-b-PHIC diblock copolymers, PHIC-b-PS-b-PHIC and PHIC-b-PI-b-PHIC triblock copolymers, PHIC-b-PI-b-PS-b-PI-b-PHIC and PHIC-b-PS-b-PI-b-PS-b-PHIC pentablock terpolymers, PS(PHIC) $)_{2}$ miktoarm stars and a PS-b-(PI-g-PHIC)block-graft terpolymer (Scheme 1). Previous studies have focused mainly on diblock and triblock copolymers containing PHIC chains, showing unique characteristics on the self-assembly properties and a tremendous influence of the rod-like nature of polyisocyanates [39,64-67]. Therefore, cylindrical micelles or vesicular structures were obtained reflecting the liquid crystalline properties of the PHIC chains. The micellization behaviour of rod-coil copolymers was not studied in depth as in the case of coil-coil copolymers. The parameter of macromolecular architecture is a new feature, which dramatically affects the self-assembly behaviour of rod-coil copolymers in selective solvents.

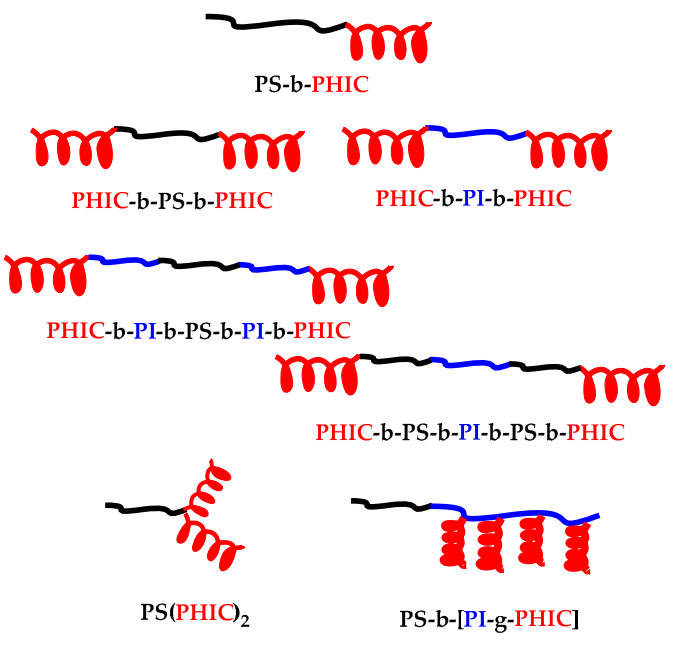

Scheme 1. Linear and nonlinear poly(n-hexyl isocyanate) (PHIC)-based block copolymers. 


\section{Materials and Methods}

\subsection{Materials}

$\mathrm{n}$-Heptane and n-dodecane used for the characterization were refluxed from calcium hydride and distilled before use. Tetrahydrofuran (THF) was refluxed over metallic sodium and distilled before use.

\subsection{Polymer Synthesis}

The polymer synthesis was accomplished through anionic and coordination polymerization techniques as previously described in the literature [44-50].

\subsection{Characterization Techniques}

Size exclusion chromatography (SEC) experiments were conducted at $40{ }^{\circ} \mathrm{C}$ using a modular instrument consisting of a Waters Model 510 pump (Waters, Milford, MA, USA), a Waters Model U6K sample injector (Waters, Milford, MA, USA), a Waters Model 401 differential refractometer Waters, Milford, MA, USA), a Waters Model 486 UV spectrophotometer (Waters, Milford, MA, USA) and a set of $4 \mu$-Styragel columns with a continuous porosity range from $500 \mathrm{~A}$ to $10^{5} \mathrm{~A}$. The columns were housed in an oven at $25^{\circ} \mathrm{C}$. THF was the carrier solvent at a flow rate of $1 \mathrm{~mL} / \mathrm{min}$.

Low-angle laser light scattering measurements were performed with a Chromatix KMX-6 photometer (Milton Roy, LDC Division, Riviera Beach, FL, USA) at $25{ }^{\circ} \mathrm{C}$ equipped with a $2 \mathrm{~mW}$ He-Ne laser operating at $\lambda=633 \mathrm{~nm}$. Equation (1) describes the concentration dependence of the reduced intensity:

$$
\frac{K c}{\Delta R_{\theta}}=\frac{1}{\overline{M_{w}}}+2 A_{2} c+\ldots
$$

where $K$ is a combination of optical and physical constants, including the refractive index increment, $d n / d c$, and the excess Rayleigh ratio of the solution over that of the solvent, $\Delta R_{\theta}$. Stock solutions were prepared, followed by dilution with the solvent to obtain appropriate concentrations. All solutions and solvents were optically clarified by filtering through $0.22-\mu \mathrm{m}$ pore size nylon filters directly into the scattering cell.

Refractive index increments, $d n / d c$, at $25^{\circ} \mathrm{C}$ were measured with a Chromatix KMX-16 (Milton Roy, LDC Division, Riviera Beach, FL, USA) refractometer operating at $633 \mathrm{~nm}$ and calibrated with aqueous $\mathrm{NaCl}$ solutions.

Dynamic light scattering measurements were conducted with a Series 4700 Malvern system (Grovewood Road. Malvern, UK) composed of a PCS5101 goniometer with a PCS stepper motor controller, a Cyonics variable power $\mathrm{Ar}^{+}$laser operating at $488 \mathrm{~nm}$, a PCS8 temperature control unit, a RR98 pump/filtering unit and a 192 channels correlator for the accumulation of the data. The correlation functions were analysed by the cumulant method and the CONTIN software [68]. Measurements were carried out at $45^{\circ}, 90^{\circ}$ and $135^{\circ}$. The angular dependence of the ratio $\Gamma / \mathrm{q}^{2}$, where $\Gamma$ is the decay rate of the correlation function and $\mathrm{q}$ is the scattering vector, was not very important for most of the micellar solutions. In these cases, apparent translational diffusion coefficients at zero concentration, $D_{0, a p p}$, were measured using Equation (2):

$$
D_{a p p}=D_{0, a p p}\left(1+k_{D} c\right)
$$

where $k_{D}$ is the coefficient of the concentration dependence of the diffusion coefficient. Apparent hydrodynamic radii at infinite dilutions, $R_{h}$, were calculated by aid of the Stokes-Einstein Equation (3):

$$
R_{h}=k T / 6 \pi \eta_{s} D_{0, a p p}
$$

where $k$ is the Boltzmann's constant, $T$ is the absolute temperature and $\eta_{s}$ is the viscosity of the solvent. 
Viscometric data were analysed using the Huggins Equation (4):

$$
\frac{\eta_{s p}}{c}=[\eta]+K_{H}[\eta]^{2} c+\ldots
$$

and the Kraemer Equation (5):

$$
\frac{\ln \eta_{r}}{c}=[\eta]+K_{K}[\eta]^{2} c+\ldots
$$

where $\eta_{r}, \eta_{s p}$ and $[\eta]$ are the relative, specific and intrinsic viscosities respectively, and $K_{H}$ and $K_{K}$ are the Huggins and Kraemer constants, respectively. All measurements were carried out at $25^{\circ} \mathrm{C}$. Cannon-Ubbelohde dilution viscometers equipped with a Schott-Geräte AVS 410 automatic flow timer were used. Viscometric radii, $R_{v}$, were calculated from Equation (6):

$$
R_{v}=\left(\frac{3}{10 \pi N_{A}}\right)^{1 / 3}\left([\eta] M_{w, a p p}\right)^{1 / 3}
$$

where $M_{w, \text { app }}$ is the weight average molecular weight determined by light scattering measurements.

Table $1 \mathrm{H}$-NMR spectra were recorded in d-chloroform at 305.0 K with a Bruker Avance III 600 NMR spectrometer (Bruker, BioSpin, Rheinstetten, Germany).

\begin{tabular}{|c|c|c|c|c|c|c|c|c|c|c|}
\hline Sample & $\begin{array}{l}M_{w} \times \\
10^{-3} \mathbf{a}\end{array}$ & $\oplus^{b}$ & $\begin{array}{l}\% \mathrm{~S}, \\
\mathrm{wt}^{\mathrm{c}}\end{array}$ & $\begin{array}{c}\mathrm{A}_{2}^{\mathrm{a}} \times \\
10^{4}\end{array}$ & $\begin{array}{c}\left(\mathrm{M}_{\mathrm{w}} \times\right. \\
\left.10^{-3}\right)_{\text {mic }}\end{array}$ & $\mathbf{N}_{\mathbf{w}}$ & $\begin{array}{c}\mathrm{D} \mathrm{cm}^{2} / \mathrm{s}^{\mathrm{d}} \\
\times 10^{8}\end{array}$ & $k_{D}{ }^{d}$ & $\mathrm{R}_{1}{ }^{\mathrm{d}}, \mathrm{nm}$ & $\mathrm{R}_{2}{ }^{\mathrm{d}}, \mathrm{nm}$ \\
\hline SH14/3/97 & 14.0 & 1.32 & 3 & -0.46 & 19.80 & 1.4 & -78.99 & 66.7 & 4.40 & - \\
\hline SH7.5/9/91 & 7.5 & 1.29 & 9 & 0.49 & 24.30 & 3.2 & 58.02 & 42.6 & $\begin{array}{c}9.41 \\
(91.8 \%)\end{array}$ & $\begin{array}{c}51.2 \\
(8.2 \%)^{\mathrm{e}}\end{array}$ \\
\hline SH19.5/11/89 & 19.5 & 1.22 & 11 & 2.00 & 161.0 & 8.3 & 9.75 & 667 & $\begin{array}{c}55.9 \\
(93.6 \%)^{\mathrm{e}}\end{array}$ & $\begin{array}{c}126.4 \\
(6.4 \%)^{\mathrm{e}}\end{array}$ \\
\hline SH14/18/82 & 14.0 & 1.18 & 18 & -0.15 & 333.0 & 23.8 & 8.0 & -12.5 & $\begin{array}{c}68.2 \\
(68.0 \%)^{\mathrm{e}}\end{array}$ & $\begin{array}{c}142.6 \\
(32 \%)^{\mathrm{e}}\end{array}$ \\
\hline SH121/90/10 & 121.0 & 1.19 & 90.4 & -35.2 & 163,300 & 1350 & 2.0 & -69.75 & 53.4 & - \\
\hline SH187/92/8 & 187.0 & 1.29 & 91.6 & -0.79 & 247,800 & 1325 & 6.93 & -470 & 79.4 & - \\
\hline
\end{tabular}

Table 1. Molecular characteristics of the SH block copolymers and their micellar characteristics in n-heptane.

${ }^{a}$ By low-angle laser light scattering (LALLS), ${ }^{b}$ by size exclusion chromatography (SEC) in tetrahydrofuran (THF),

${ }^{\mathrm{c}}$ by ${ }^{1} \mathrm{H}$ NMR in $\mathrm{CDCl}_{3}$ at $25^{\circ} \mathrm{C}$, d by dynamic light scattering (DLS) in n-heptane, ${ }^{\mathrm{e}}$ by DLS in $\mathrm{n}$-heptane.

Atomic force microscopy (AFM) was performed with a Nanoscope IIIa Microscope with a multimode controller (Veeco Instruments, Plainview, NY, USA) at ambient temperature. Drop cast films were prepared on a freshly prepared mica surface from a sample concentration of $1 \mathrm{mg} \mathrm{mL}^{-1}$ in suitable solvent. The tapping mode was employed with an antimony-doped $\mathrm{Si}$ tip (radius $<10 \mathrm{~nm}$ ) at a line scanning frequency of $1 \mathrm{~Hz}$.

\section{Results}

\subsection{Micellization Behavior of PS-b-PHIC, SH Block Copolymers in n-Heptane}

The diblock copolymers having polystyrene (PS) and PHIC blocks were synthesized either by anionic (SH121/90/10 and SH187/92/8) or by coordination polymerization techniques (SH14/3/97, SH7.5/9/91, SH19.5/11/89 and SH14/18/82) [44-50]. The samples are symbolized as SH followed by numbers denoting the sample's molecular weight (in KDa), the \% wt content is PS and the \% wt content in PHIC. The molecular characteristics are given in Table 1. The micellar solutions were obtained in n-heptane, which is a selective solvent for the PHIC block. In other words, the micelles consist of a core from the amorphous and glassy PS chains and a soluble corona from the rod-like PHIC chains. The samples with the rather small amount of PS were directly dissolved in the selective solvent. 
The dissolution was facilitated by heating the n-heptane solution at $60^{\circ} \mathrm{C}$ under argon atmosphere overnight. Taking into account the low molecular weight of the PS blocks and their subsequently lower Tg values, this thermal treatment is able to provide enough mobility to the PS blocks in order to achieve the formation of equilibrium micellar structures. The last two samples with the highest PS content were not directly soluble in the selective solvent. In this case, the micellization was promoted by dissolving the block copolymers in a mixture of the selective solvent along with the minimum amount of the common good solvent THF. In this mixture, the block copolymers are readily dissolved and gradual evaporation of the volatile THF leaves stable micellar solutions with the characteristic blue tint, which ensures the formation of large supramolecular structures. All micellar solutions were stable over a period of several weeks.

The LALLS data of the linear SH block copolymers in n-heptane are given in Table 1, whereas characteristic plots are provided in Figure 1. The weight average degree of association, $\mathrm{N}_{\mathrm{w}}$, defined as the ratio of $\mathrm{M}_{\mathrm{W}}$ measured in the selective solvent over $\mathrm{M}_{\mathrm{W}}$ of the diblock in the common good solvent THF, increases upon increasing the PS content. Sample SH14/3/97 with only 3\% wt PS leads to almost unimolecular micelles with an average degree of association, $\mathrm{N}_{\mathrm{W}}$, equal to 1.4. Going to the extreme case, where PS dominates within the copolymer structure (samples SH121/90/10 and SH187/92/8 containing more than $90 \%$ PS), the $\mathrm{N}_{\mathrm{w}}$ values increase dramatically to more than 1300 . The LALLS plots for samples SH14/3/97, SH7.5/9/81, SH19.5/11/89 and SH14/18/82 are linear over the concentration range examined, i.e., the critical micelle concentration (CMC) is much lower than the lowest experimentally accessible concentration (approximately $2 \times 10^{-3} \mathrm{~g} / \mathrm{mL}$ ), and stable micellar structures exist in that concentration regime. Samples SH121/90/10 and SH187/92/8 show stable micellar structures at concentrations higher than $1.5 \times 10^{-5} \mathrm{~g} / \mathrm{mL}$. At lower concentrations, much lower apparent molecular weights were obtained, indicating the ongoing association process. However, even for these two samples, it was not possible to identify the CMC values by LALLS measurements. The LALLS plots for these samples are incorporated in the Supplementary Materials Section, SMS. The second virial coefficients are very low, even in the cases of micelles with low $N_{w}$ values, indicating weak interactions of the supramolecular species and the selective solvent.

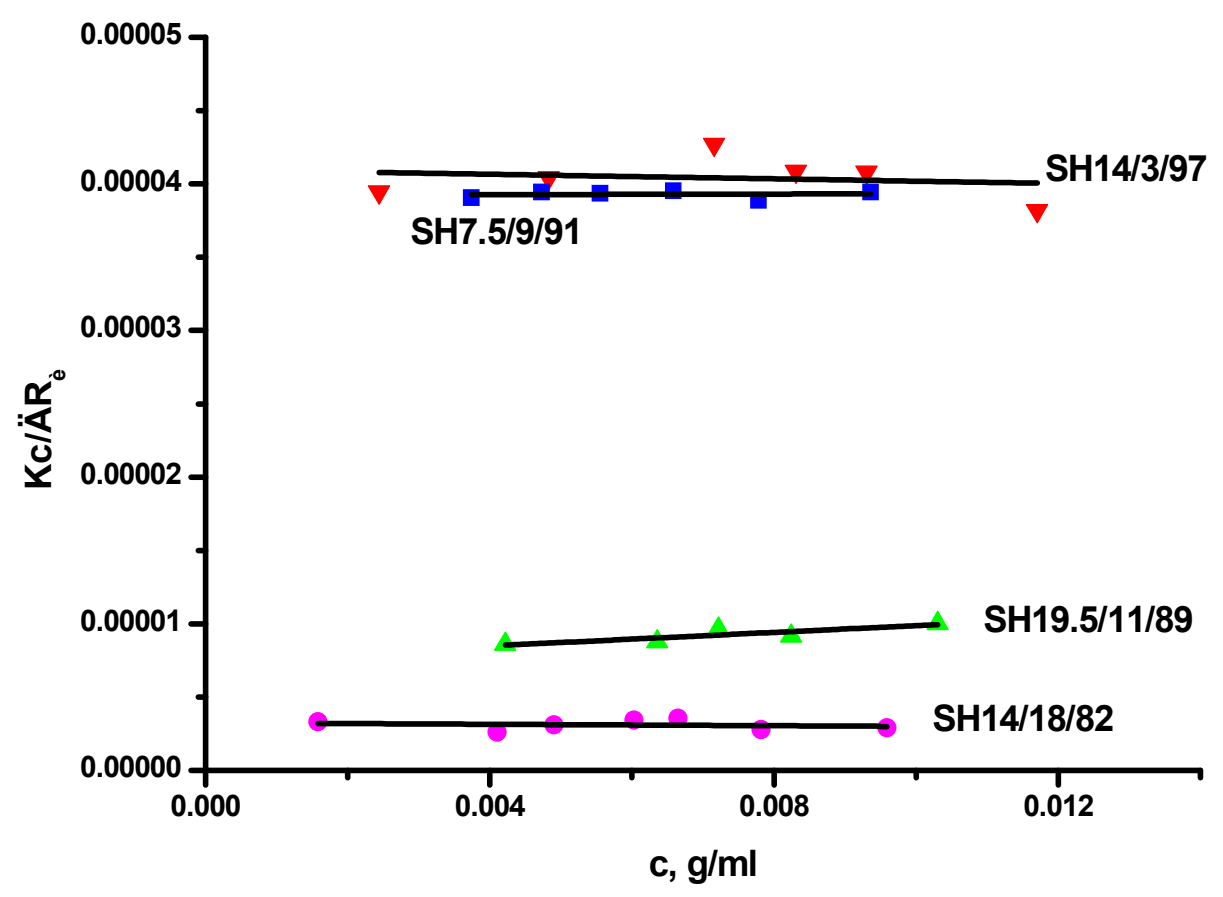

Figure 1. LALLS plots of SH block copolymers in n-heptane.

The DLS data of block copolymers in n-heptane are given in Table 1. The plots are linear (characteristic examples are given in the SMS) but with very low $\mathrm{k}_{\mathrm{D}}$ values. This result is in agreement 
with the low $A_{2}$ values obtained in the selective solvent, since $k_{D}$ and $A_{2}$ are related through the following equation:

$$
\mathrm{k}_{\mathrm{D}}=2 \mathrm{~A}_{2} \mathrm{M}+\mathrm{k}_{\mathrm{f}}-\mathrm{u}
$$

where $\mathrm{M}$ is the molecular weight, $\mathrm{k}_{\mathrm{f}}$ is the coefficient of the concentration dependence of the friction coefficient and $\mathrm{u}$ is the partial specific volume of the polymer. Due to the similar molecular weights in both solvents, THF and n-heptane, a decrease in $A_{2}$ is accompanied by a decrease in $\mathrm{k}_{\mathrm{D}}$ as well. CONTIN analysis provided suitable insight into the self-assembly process and the formation of the supramolecular structures.

Sample SH14/3/97, with the lowest PS content, forms very small spherical structures, as revealed by their low size along with the absence of any angular dependence in DLS measurements. The polydispersity factor $\mu_{2} / \Gamma^{2}$, where $\Gamma$ is the decay rate of the correlation function and $\mu_{2}$ is the second moment of the cumulant analysis, is always lower than 0.1 , indicating the presence of monodisperse small micellar structures.

CONTIN analysis for samples SH7.5/9/81, SH19.5/11/89 and SH14/18/82 revealed the presence of bimodal distributions, indicating the presence of higher-order equilibrium in solution. Judging from the relative $R_{h}$ values of the different populations, it is obvious that equilibrium between micelles and clusters exist. For samples SH19.5/11/89 and SH7.5/9/91, the clusters are the minority component (less than $10 \%$ by intensity), but for sample SH14/18/82, the contribution of the clusters is much more pronounced (higher than $30 \%$ by intensity). In all cases, however, the micelles are spherical (there is no angular dependence) and thermally stable up to $55^{\circ} \mathrm{C}$. In addition, the micelles are almost monodispersed, taking into account the lower than 0.1 values of the polydispersity factor $\mu_{2} / \Gamma^{2}$.

Samples SH121/90/10 and SH187/92/8 with the highest $\mathrm{N}_{\mathrm{W}}$ values show unimodal distributions in CONTIN analysis. As revealed in the other cases, the micelles are spherical and monodispersed with polydispersity factor values $\mu_{2} / \Gamma^{2}$ of 0.05 . They are also thermally stable up to $55^{\circ} \mathrm{C}$. Despite the very high $N_{w}$ values of samples $S H 121 / 90 / 10$ and $S H 187 / 92 / 8$, their $R_{h}$ values are not so high, indicating that the micelles are very compact and behave more or less as hard spheres.

The thermal stability of all micelles can be explained considering that the core material is the amorphous and glassy PS with high Tg value and, more importantly, that the corona material is the stiff and helical PHIC, which does not appreciably change conformation at the temperature range examined in this work.

Several theoretical models have been proposed to describe the micelle structure. The case of micelles consisting of small cores and large coronas can be well described by the star model. If $\mathrm{N}_{\mathrm{A}}$ and $\mathrm{N}_{\mathrm{B}}$ are the lengths of the corona and core-forming blocks $A$ and $\mathrm{B}$, respectively, the star model will be valuable when $N_{A}>N_{B}$. According to the Halperin's star model [69], the following scaling relationships between the parameters of interest for block copolymers can be obtained:

$$
\begin{gathered}
\text { Aggregation number } N \sim N_{B}^{4 / 5} \\
\text { Core radius } R_{C} \sim N_{B}^{3 / 5} \\
\text { Micelle radius } R \sim N_{B}^{4 / 25} N_{A}^{3 / 5}
\end{gathered}
$$

The other limiting case is the situation of micelles consisting of a large core and a relatively thin corona, i.e., when $\mathrm{N}_{\mathrm{B}}>>\mathrm{N}_{\mathrm{A}}$ can be described by mean density models [70-72]. According to these models, the volume fraction of the A segments in the corona is assumed to be independent of the distance from the core. The following scaling relationships are obtained:

$$
\text { Aggregation number } N \sim N_{B}
$$

Core radius $R_{C} \sim N_{B}^{2 / 3}$

Micelle radius $R \sim N_{B}^{2 / 3}$ 
To further test the validity of these models, the radius of the micellar core was calculated using the following equation:

$$
\mathrm{R}_{\mathrm{c}}=\left(3 \mathrm{M}_{\mathrm{w}, \mathrm{mic}} \mathrm{wt}_{\mathrm{PS}} / 4 \pi \mathrm{N}_{\mathrm{A}} \mathrm{d}_{\mathrm{PS}} \varphi_{\mathrm{PS}}\right)^{1 / 3}
$$

where $\mathrm{M}_{\mathrm{w} \text {,mic }}$ is the micellar molecular weight, $\mathrm{wt}_{\mathrm{PS}}$ is the weight fraction of the core-forming block, $\mathrm{d}_{\mathrm{PS}}$ is the density of PS and $\varphi_{\mathrm{PS}}$ is the volume fraction of PS in the core. The density of PS is equal to $1.05\left(\mathrm{~d}_{\mathrm{PS}}=1.05\right)$. Two limiting cases were considered: the dry core $\left(\varphi_{\mathrm{PS}}=1\right)$ and the swollen core $\left(\varphi_{\mathrm{PS}}=0.5\right)$. The results for both cases are given in Table 2 . In addition, the area of the core-corona interface, $A_{c}$, occupied per copolymer chain is given as follows:

$$
\mathrm{A}_{\mathrm{c}}=4 \pi \mathrm{R}_{\mathrm{c}}^{2} / \mathrm{N}_{\mathrm{w}}
$$

The $\mathrm{A}_{\mathrm{c}}$ values for the dry and swollen core cases are also reported in Table 2.

Table 2. Structural characteristics of the SH block copolymers micelles in n-heptane.

\begin{tabular}{cccccccccc}
\hline \multirow{2}{*}{ Sample } & \multirow{2}{*}{$\mathbf{N}_{\mathbf{B}}$} & \multirow{2}{*}{$\mathbf{N}_{\mathbf{A}}$} & \multirow{2}{*}{$\mathbf{R}_{\mathbf{h}, \mathbf{n m}}$} & \multirow{2}{*}{$\mathbf{R}_{\mathbf{h}} / \mathbf{N}_{\mathbf{B}}{ }^{2 / 3}$} & \multirow{2}{*}{$\mathbf{R}_{\mathbf{h}} / \mathbf{N}_{\mathbf{B}}{ }^{\mathbf{4} / 25} \mathbf{N}_{\mathbf{A}}{ }^{3 / 5}$} & \multicolumn{2}{c}{ Dry Core } & \multicolumn{2}{c}{ Swollen Core } \\
\cline { 7 - 10 } & & & & & & $\mathbf{R}_{\mathbf{c}}, \mathbf{n m}$ & $\mathbf{A}_{\mathbf{c}}, \mathbf{n m}^{\mathbf{2}}$ & $\mathbf{R}_{\mathbf{c}}, \mathbf{n m}$ & $\mathbf{A}_{\mathbf{c}}, \mathbf{n m}^{\mathbf{2}}$ \\
\hline SH14/3/97 & 4.04 & 106.9 & 4.40 & 1.73 & 0.21 & 0.61 & 3.31 & 0.76 & 5.26 \\
SH7.5/9/91 & 6.49 & 53.74 & 9.41 & 2.70 & 0.64 & 0.94 & 3.46 & 1.18 & 5.48 \\
SH19.5/11/89 & 20.62 & 136.65 & 55.9 & 7.43 & 1.80 & 1.88 & 5.37 & 2.37 & 8.53 \\
SH14/18/82 & 24.23 & 90.39 & 68.2 & 8.14 & 2.74 & 2.83 & 4.22 & 3.56 & 6.70 \\
SH121/90/10 & 1647.0 & 91.5 & 53.4 & 0.52 & 1.17 & 38.2 & 1.12 & 48.12 & 2.37 \\
SH187/92/8 & 1051.8 & 123.7 & 79.4 & 0.57 & 1.35 & 44.1 & 0.97 & 55.68 & 1.17 \\
\hline
\end{tabular}

Judging from the high PS content of samples SH121/90/10 and SH187/92/8, it is obvious that the micellar core should be extended and that the supramolecular structures should behave as crew-cut micelles. This assumption was verified by the almost stable values of the ratio $R_{h} / N_{B}{ }^{2 / 3}$, the high values of $R_{c}$ compared to the corresponding $R_{h}$ of the micelles and the low $A_{c}$ values considering both the dry and the swollen core cases.

On the other hand, the low PS contents of samples SH14/3/97, SH7.5/9/81, SH19.5/11/89 and SH14/18/82 support the application of the star model for their micellar structures. The $\mathrm{R}_{\mathrm{h}} /\left(\mathrm{N}_{\mathrm{B}}{ }^{4 / 25} \mathrm{~N}_{\mathrm{A}}{ }^{3 / 5}\right)$ ratios were, nevertheless, not very stable as would be expected. The reason for this is the fact that there is a small but recorded tendency for the formation of clusters through intermicellar association, which causes deviations from the pure star model, and most importantly that the PHIC corona material is actually very stiff and does not change easily conformations. The star model is more adequate for flexible polymeric chains. However, the relatively low $R_{c}$ and high $A_{c}$ values are more consistent with a star-like structure. These conclusions will be further confirmed by AFM measurements.

\subsection{Micellization Behavior of PHIC-b-PS-b-PHIC, HSH, Triblock Copolymers in n-Heptane and PHIC-b-PI-b-PHIC, HIH, Triblock Copolymer in n-Dodecane}

The symmetric triblock copolymers PHIC-b-PS-b-PHIC and PHIC-b-PI-b-PHIC containing PS or polyisoprene (PI) as the middle block were synthesized by anionic polymerization high vacuum techniques [47]. The samples are symbolized as $\mathrm{HSH}$ and $\mathrm{HIH}$, respectively. The HSH samples are differentiated by the numbers indicating the sample's molecular weight (in KDa), the \% wt content in PS and the \% wt content in PHIC. The molecular characteristics of the samples are given in Table 3. The HSH samples were dissolved in n-heptane, which is selective for the PHIC chains. In order to facilitate the dissolution and achieve equilibrium structures, the solutions were heated at $60{ }^{\circ} \mathrm{C}$ overnight in argon atmosphere. PHIC and PI are soluble in n-heptane, and therefore, the HIH copolymer was dissolved in n-dodecane, which is selective for the PI chains. The static and dynamic light scattering data are given in Table 3, whereas characteristic LALLS plots are provided in Figure 2. DLS plots are also given in the SMS. The LALLS plot is linear for HIH-forming structures with a very low $\mathrm{N}_{\mathrm{w}}$ value. Therefore, almost unimolecular micelles are promoted in $\mathrm{n}$-dodecane. In low 
concentrations, the formation of unimolecular micelles is favoured due to the rather low PHIC content in the copolymer $(16 \% \mathrm{wt})$. The linear chains form loops in order to accommodate together the insoluble PHIC chains. This is facilitated by the presence of the flexible and soluble PI block, which is placed at the middle of the structure. These intramolecular associates through loop formation are in equilibrium with intermolecular associates or clusters, leading to higher degrees of aggregation. This equilibrium is shifted towards the clusters upon increasing the concentration. This behaviour has been observed in the case of micellar formation from triblock copolymers in solvents selective for the middle block [73-77].

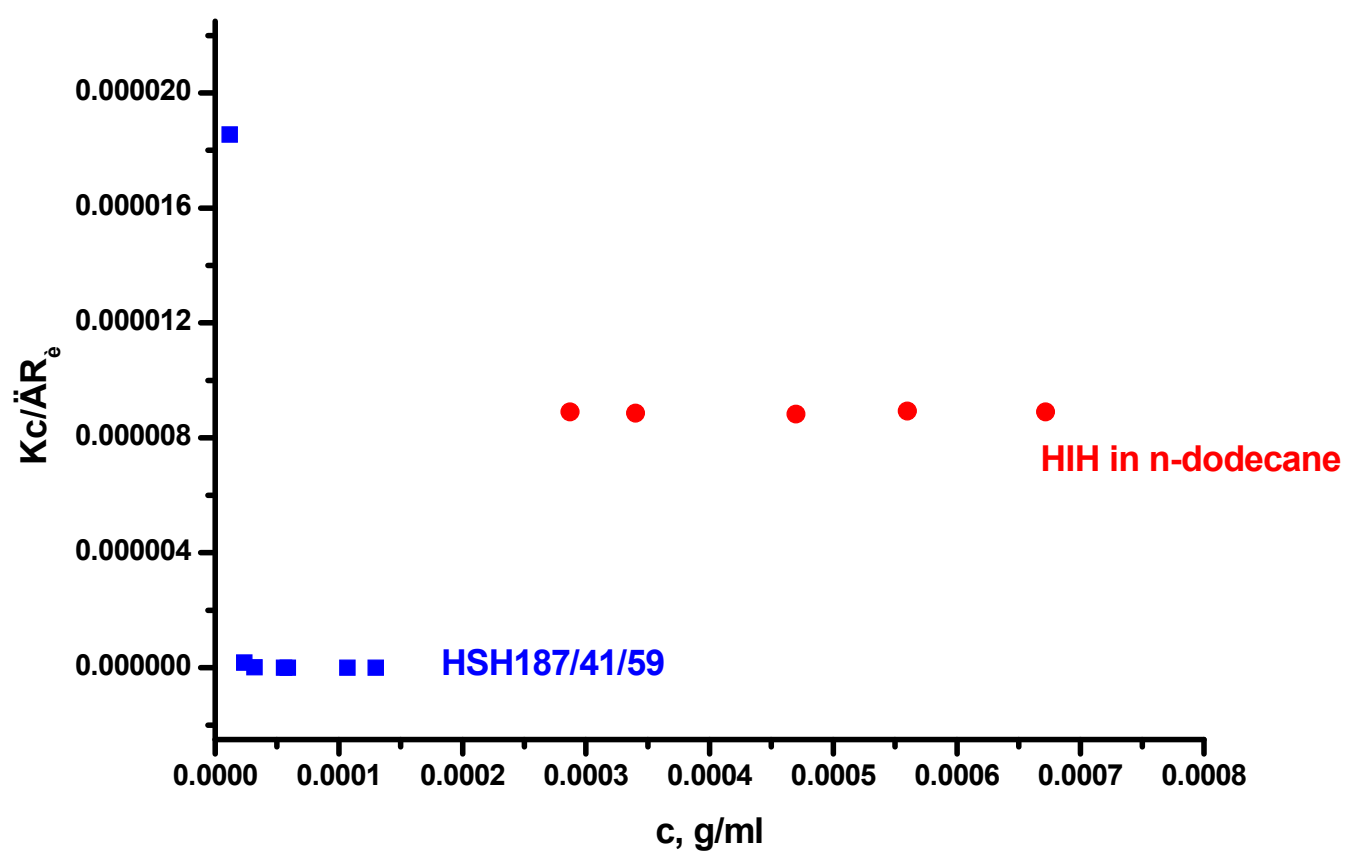

Figure 2. LALLS plots of triblock copolymers HSH\#2 in n-heptane and HIH in n-dodecane.

The HSH samples form multimolecular micelles with $\mathrm{N}_{\mathrm{W}}$ values equal to 43.5 and 102 . The sample with the higher PS content has the higher degree of association, as expected. However, these values are lower than those expected, taking into account the corresponding diblock copolymers, indicating that the splitting of the PHIC chain to two parts surrounding the insoluble corona leads to more soluble supramolecular structures and, therefore, to lower $\mathrm{N}_{\mathrm{w}}$ values. The LALLS plots are linear for concentrations higher than $10^{-5} \mathrm{~g} / \mathrm{mL}$. At lower concentrations, lower apparent molecular weights are observed, verifying that, at this concentration regime, micellar organization takes place. However, the experimental data are not sufficient to provide the CMC value for these triblock copolymers. Finally, the $\mathrm{A}_{2}$ values are slightly negative, as a result of the reduced interactions between the triblock copolymer and the selective solvent. The macromolecular architecture definitely plays an important role influencing the micellization behaviour. 
Table 3. Molecular characteristics of the HSH and HIH triblock copolymers and their micellar characteristics in n-heptane and n-dodecane, respectively.

\begin{tabular}{|c|c|c|c|c|c|c|c|c|c|c|c|c|}
\hline \multirow{2}{*}{ Sample } & \multirow{2}{*}{$M_{w} \times 10^{-3}$ a } & \multirow{2}{*}{$\mathbf{D}^{\mathrm{b}}$} & \multirow{2}{*}{$\% S\left(\right.$ or I), $w^{c}{ }^{c}$} & \multirow{2}{*}{$\mathrm{A}_{2}{ }^{\mathrm{a}} \times 10^{5}$} & \multirow{2}{*}{$\left(\mathrm{M}_{\mathrm{w}} \times 10^{-3}\right)_{\mathrm{mic}}{ }^{\mathrm{a}}$} & \multirow{2}{*}{$\mathbf{N}_{\mathbf{w}}$} & \multicolumn{3}{|c|}{ THF } & \multicolumn{3}{|c|}{ n-Heptane or n-Dodecane } \\
\hline & & & & & & & $\mathrm{D} \mathrm{cm}^{2} / \mathrm{s}^{\mathrm{d}} \times 10^{8}$ & $k_{D}{ }^{d}$ & $\mathrm{R}^{\mathrm{d}}, \mathrm{nm}$ & $\mathrm{D} \mathrm{cm}^{2} / \mathrm{s}^{\mathrm{d}} \times 10^{8}$ & $k_{D}{ }^{d}$ & $\mathrm{R}^{\mathrm{d}}, \mathrm{nm}$ \\
\hline HSH102/46/54 & 102.0 & 1.11 & 46.0 & 3.27 & 10,404 & 102 & 30.86 & 56.32 & 26.1 & 2.34 & -56.40 & 70.9 \\
\hline HSH187/41/59 & 187.3 & 1.36 & 41.0 & 0.84 & 8147.6 & 43.5 & 48.48 & 37.50 & 16.6 & 2.88 & -69.75 & 56.7 \\
\hline $\mathrm{HIH}$ & 83.25 & 1.11 & 84.0 & 3.51 & 113.0 & 1.36 & 39.52 & 45.90 & 12.0 & 18.848 .42 & $\begin{array}{c}9.8^{\mathrm{e}} \\
-178.3\end{array}$ & $\begin{array}{l}8.4(90 \%)^{\mathrm{e}} \\
18.8(10 \%)\end{array}$ \\
\hline
\end{tabular}

${ }^{\text {a }}$ By LALLS, ${ }^{\text {b }}$ by SEC in THF, ${ }^{\mathrm{c}}$ by ${ }^{1} \mathrm{H}$ NMR in $\mathrm{CDCl}_{3}$ at $25^{\circ} \mathrm{C},{ }^{\mathrm{d}}$ by DLS in $\mathrm{n}$-heptane and ${ }^{\mathrm{e}}$ by DLS in $\mathrm{n}$-dodecane and CONTIN analysis. 
The DLS data are displayed in Table 3. Results in the selective solvent and in the common good solvent THF are also provided. The sample HIH revealed bimodal distribution in CONTIN analysis. The major component (approximately $90 \%$ by intensity) has slightly lower $\mathrm{R}_{\mathrm{h}}$ values compared to that measured in THF, confirming the formation of mainly unimolecular micelles in n-dodecane. The second minor population revealed a much higher $R_{h}$ value, which can be attributed to a small amount of multimolecular micelles. These results confirm the previous discussion referring to the presence of equilibrium between intramolecular (loops formation) and intermolecular aggregates (clusters). This conclusion will be further supported by AFM images. The triblock HSH on the other hand showed unimolecular peaks in the CONTIN analysis. The absence of angular dependence and the low polydispersity factor confirms the presence of spherical and monodisperse micellar structures. In addition, these supramolecular structures are thermally stable up to $55^{\circ} \mathrm{C}$. For the $\mathrm{HSH}$ triblocks viscometry measurements in dilute solution were conducted as well. The results are given in Table 4 , and the viscometry plots are included in the SMS. Very high $\mathrm{k}_{\mathrm{H}}$ values were obtained as a result of the strong hydrodynamic interactions in solution, as expected in highly associated systems. The viscometric radii, $R v$, were in very close agreement with the corresponding $R_{h}$ values, confirming the formation of stable and spherical micelles in n-heptane. The structural characteristics of the HSH micelles are shown in Table 5. Comparing the $R_{c}$ with the corresponding $R_{h}$ values, it is obvious that the cores are not very extended and are relatively compact. The area of the core-corona interface, $\mathrm{A}_{\mathrm{c}}$, occupied per copolymer chain is much higher in the case of the triblock copolymer micelles than that of the diblock copolymer micelles. This result clearly indicates the effect of the macromolecular architecture on the micellization process.

Table 4. Viscometry results of the HSH triblock copolymers in n-heptane.

\begin{tabular}{ccccc}
\hline Sample & {$[\boldsymbol{\eta}], \mathbf{d l} / \mathbf{g}$} & $\mathbf{R}_{\mathbf{v}}, \mathbf{n m}$ & $\mathbf{k}_{\mathbf{H}}$ & $\mathbf{R}_{\mathbf{v}} / \mathbf{R}_{\mathbf{h}}$ \\
\hline HSH102/46/54 & 193.85 & 68.3 & 1.23 & 0.96 \\
HSH187/41/59 & 92.17 & 49.3 & 0.63 & 0.87 \\
\hline
\end{tabular}

Table 5. Structural characteristics of the HSH triblock copolymer micelles in n-heptane.

\begin{tabular}{ccccc}
\hline \multirow{2}{*}{ Sample } & \multicolumn{2}{c}{ Dry Core } & \multicolumn{2}{c}{ Swollen Core } \\
\cline { 2 - 5 } & $\mathbf{R}_{\mathbf{c}}, \mathbf{n m}$ & $\mathbf{A}_{\mathbf{c}}, \mathbf{n m}^{\mathbf{2}}$ & $\mathbf{R}_{\mathbf{c}}, \mathbf{n m}$ & $\mathbf{A}_{\mathbf{c}}, \mathbf{n m}^{\mathbf{2}}$ \\
\hline HSH102/46/54 & 12.17 & 18.27 & 15.34 & 29.01 \\
HSH187/41/59 & 10.80 & 33.72 & 13.61 & 53.52 \\
\hline
\end{tabular}

3.3. Micellization Behavior of PHIC-b-PS-b-PI-b-PS-b-PHIC, HSISH, and PHIC- $b$-PI- $b$-PS-b-PI- $b$-PHIC, HISIH, Pentablock Terpolymers in n-Heptane and in n-Dodecane

The pentablock terpolymers were synthesized by anionic polymerization and high vacuum techniques [47] and are denoted as HSISH and HISIH. The molecular characteristics of the samples along with their LALLS and DLS data in the common good solvent, THF, and in the selective solvents are given in Table 6. Both solvents are precipitants for the PS chains. On the other hand, n-heptane is a good solvent for PI and PHIC but n-dodecane is a non-solvent for PHIC and PS blocks. The LALLS data for the HSISH in either selective solvent revealed high $\mathrm{N}_{\mathrm{w}}$ values. The LALLS plots are given in Figure $3 \mathrm{a}, \mathrm{b}$. The $\mathrm{N}_{\mathrm{w}}$ value was considerably higher in $\mathrm{n}$-dodecane than in $\mathrm{n}$-heptane. This difference is reasonable since n-heptane is a good solvent for both PHIC and PI chains, whereas n-dodecane is a good solvent only for the PI chains. The micelles of the pentablocks in n-dodecane should have a similar behaviour with the corresponding HSH triblock copolymers in n-heptane, since in both cases the middle block is insoluble. A peculiar behaviour should be expected in $n$-heptane, since the insoluble PS blocks are the intermediate blocks in the structure. This may give rise to intermicellar interactions and thus to the formation of more complex supramolecular structures. This will be further confirmed by AFM images. 
Table 6. Molecular characteristics of the HSISH and HISIH pentablock terpolymers and their micellar characteristics in $\mathrm{n}$-heptane and $\mathrm{n}$-dodecane.

\begin{tabular}{|c|c|c|c|c|c|c|c|c|c|c|}
\hline Sample & $\mathrm{D}^{\mathrm{a}}$ & $\underset{\mathrm{b}}{\mathrm{w}}, \mathrm{wt}$ & $\underset{b}{\% I ~ w t ~}$ & $\underset{b}{\% H}$ wt & Solvent & $M_{w} \times 10^{-3 c}$ & $\mathrm{~A}_{2}{ }^{\mathrm{c}}$ & $\mathrm{R}_{\mathrm{h}}{ }^{\mathrm{d}}, \mathrm{nm}$ & $k_{D}{ }^{d}$ & $\mathbf{N}_{\mathbf{w}}$ \\
\hline \multirow{3}{*}{ HSISH } & \multirow{3}{*}{1.25} & \multirow{3}{*}{46} & \multirow{3}{*}{41} & \multirow{3}{*}{13} & THF & 99.250 & $5.2 \times 10^{-4}$ & 13.6 & 53.6 & - \\
\hline & & & & & $\mathrm{C} 7$ & $21,600.00$ & $1.68 \times 10^{-6}$ & $\begin{array}{c}32.5 \\
62.8(54 \%) \mathrm{e}\end{array}$ & $30.1-32.2$ & 217.6 \\
\hline & & & & & $\mathrm{C} 12$ & $62,000.00$ & $1.55 \times 10^{-7}$ & $\begin{array}{c}39.0 \\
93.2(53 \%)^{\mathrm{e}}\end{array}$ & $38.4-39.6$ & 624.7 \\
\hline \multirow{3}{*}{ HISIH } & \multirow{3}{*}{1.32} & \multirow{3}{*}{43} & \multirow{3}{*}{32} & \multirow{3}{*}{25} & THF & 169.00 & 0.15 & 17.0 & 42.7 & - \\
\hline & & & & & $\mathrm{C} 7$ & 717.00 & 0.12 & $\begin{array}{c}47.1 \\
109.4(49 \%)^{\mathrm{e}}\end{array}$ & 38.30 .05 & 4.24 \\
\hline & & & & & $\mathrm{C} 12$ & 1492.30 & 0.26 & $\begin{array}{c}32.0 \\
78.4(58 \%) \mathrm{e}\end{array}$ & 12.74 .7 & 8.83 \\
\hline
\end{tabular}

${ }^{\text {a }}$ By SEC in THF, by ${ }^{1} \mathrm{H}$ NMR in $\mathrm{CDCl}_{3}$ at $25^{\circ} \mathrm{C}^{\mathrm{c}}$ by LALLS, ${ }^{\mathrm{d}}$ by DLS in $\mathrm{n}$-heptane or $\mathrm{n}$-dodecane and ${ }^{\mathrm{e}}$ by CONTIN analysis.

The pentablock terpolymer HISIH forms aggregates in both solvents. As in the case of the previous terpolymer, the degree of association is higher in n-dodecane than in n-heptane (Figure $3 b$ ). However, in both solvents, the $\mathrm{N}_{\mathrm{W}}$ values are much lower compared to the HISIH terpolymer. This is the result of the different macromolecular architecture. The rearrangement of the blocks within the molecular structure has a tremendous effect on the aggregation behaviour. The insoluble PS block is now located at the middle of the structure and is surrounded by four soluble blocks in n-heptane. The soluble intermediate PI blocks are the minority components interfering the insoluble PS and PHIC blocks, thus restricting the association process and leading to a relatively small degree of association in n-dodecane as well.

The DLS measurements reveal a more complex association behaviour in both selective solvents. The DLS plots are provided in Figure $4 \mathrm{a}, \mathrm{b}$ or Figure 5a,b. It is obvious that, in all cases, there is equilibrium between micellar structures and clusters. This is confirmed by CONTIN analysis showing two respective populations. The first population is angular independent, and the particles have low dispersity (polydispersity factor $\mu_{2} / \Gamma^{2}<0.2$ ). On the contrary, the second population is attributed to non-spherical (there is angular dependence) and rather polydisperse particles $\left(\mu_{2} / \Gamma^{2}>0.2\right)$ and has a much higher $R_{h}$ values compared to the first population. The $k_{D}$ values were reasonably lower than those measured in the common good solvent THF, and even lower values were observed for the clusters' populations. Although the HSISH terpolymer has much higher degrees of association, the structures have lower $R_{h}$ values than that of the pentablock HISIH. These results indicate that more compact supramolecular structures are produced from the HSISH terpolymer. 


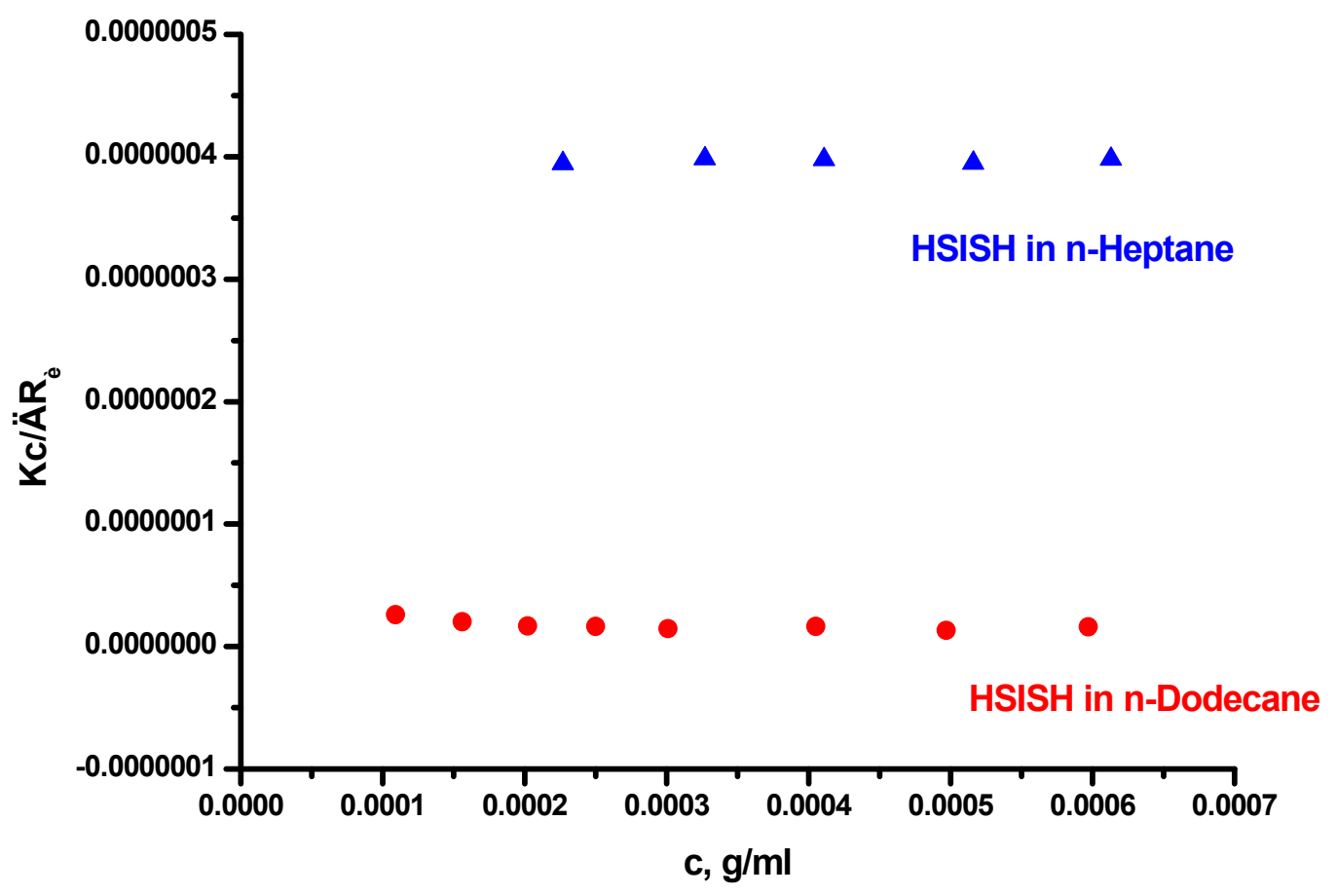

(a)

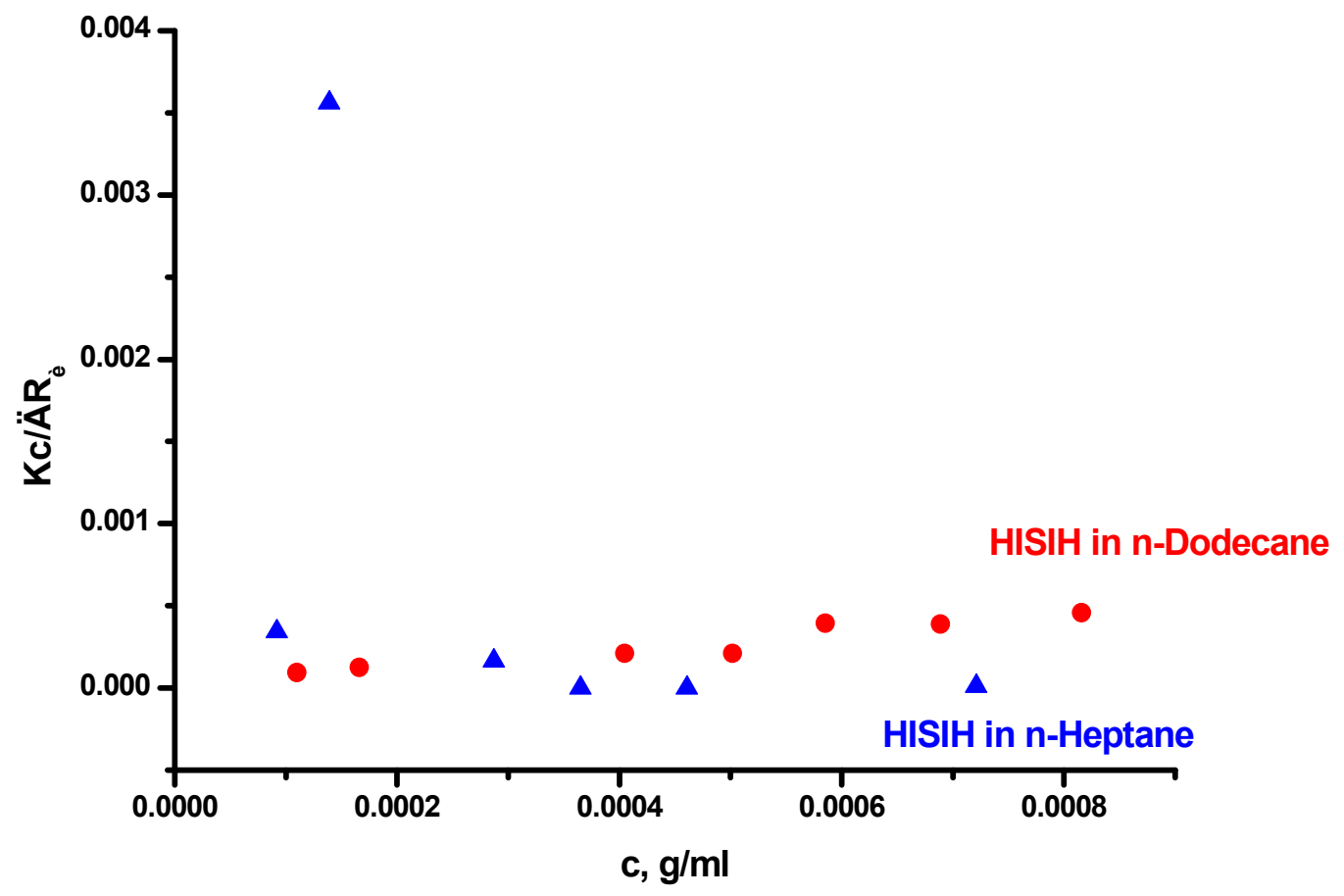

(b)

Figure 3. (a) LALLS plots of the HSISH pentablock terpolymer in n-heptane and n-dodecane and (b) LALLS plots of the HISIH pentablock terpolymer in n-heptane and n-dodecane. 


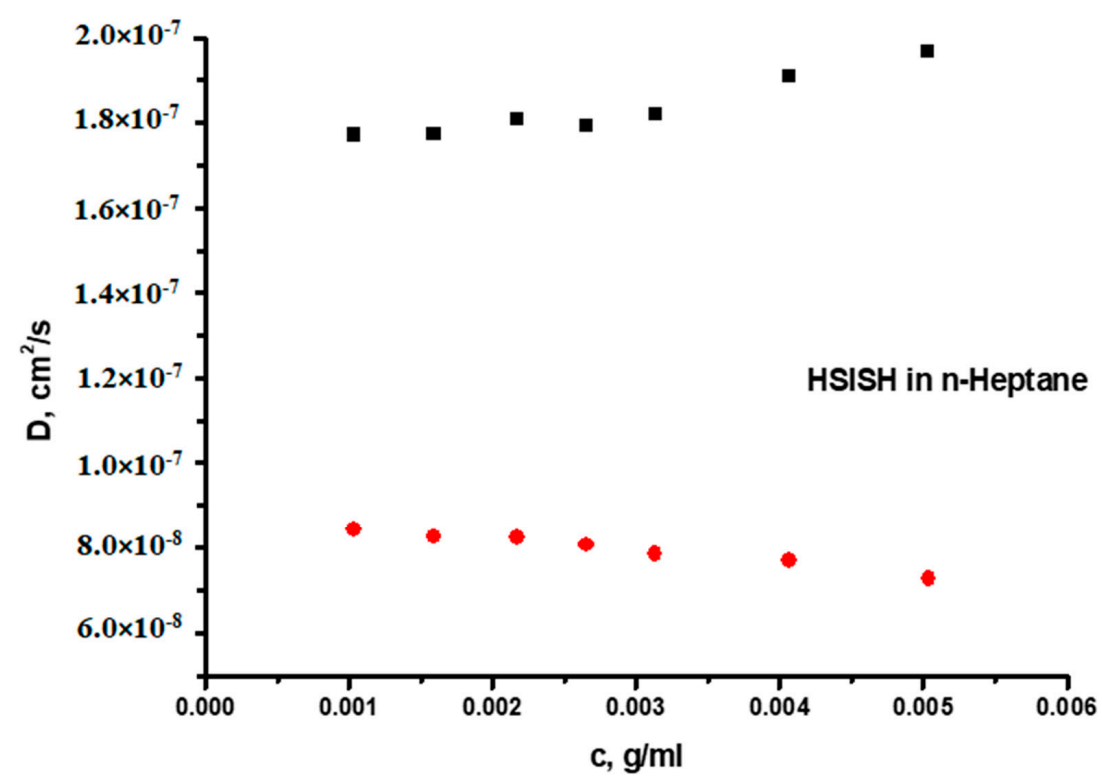

(a)

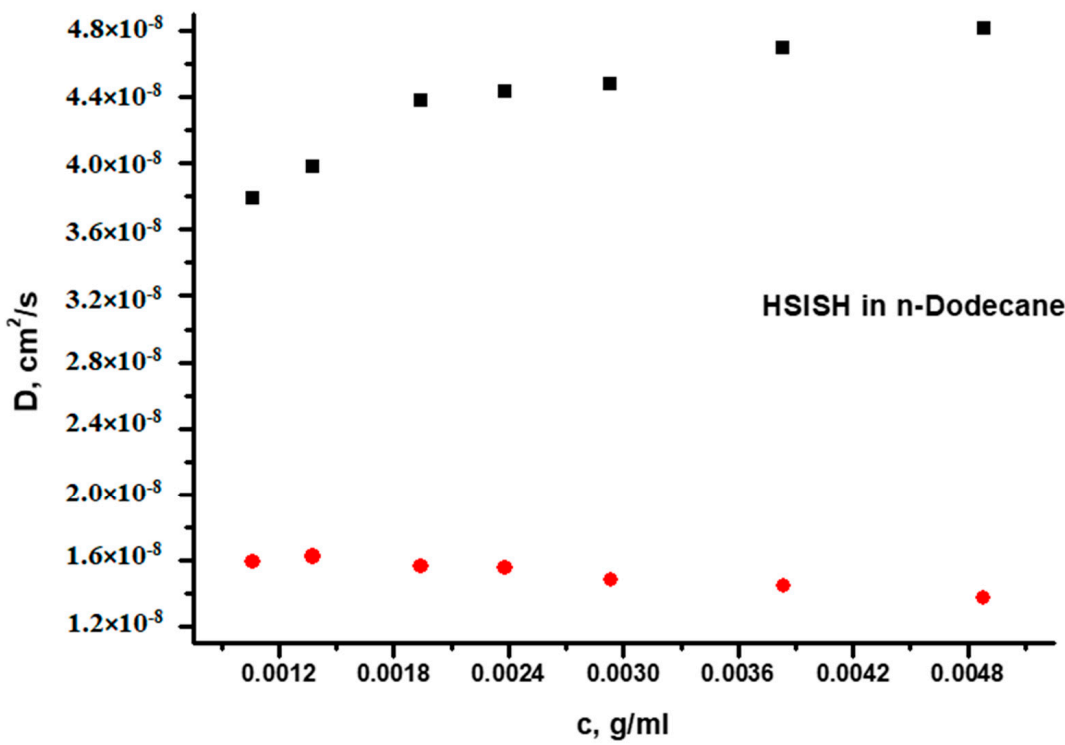

(b)

Figure 4. (a) DLS plots of the two populations of the HSISH pentablock terpolymer in n-heptane and (b) DLS plots of the two populations of the HSISH pentablock terpolymer in n-dodecane. 


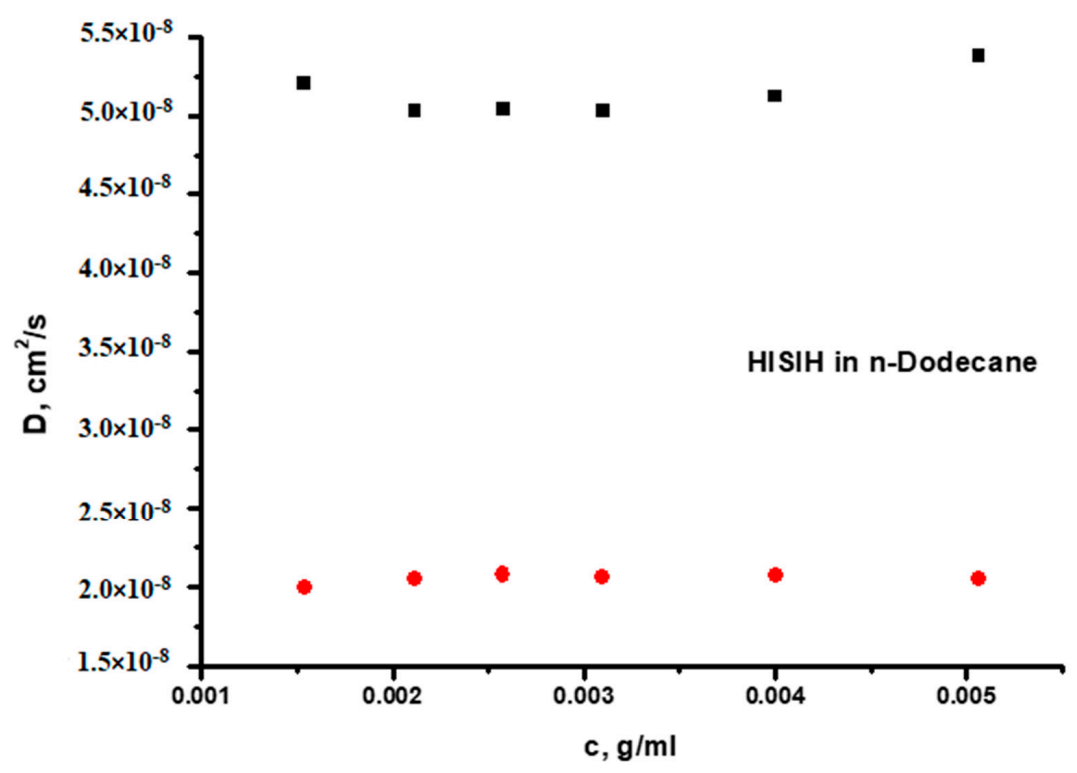

(a)

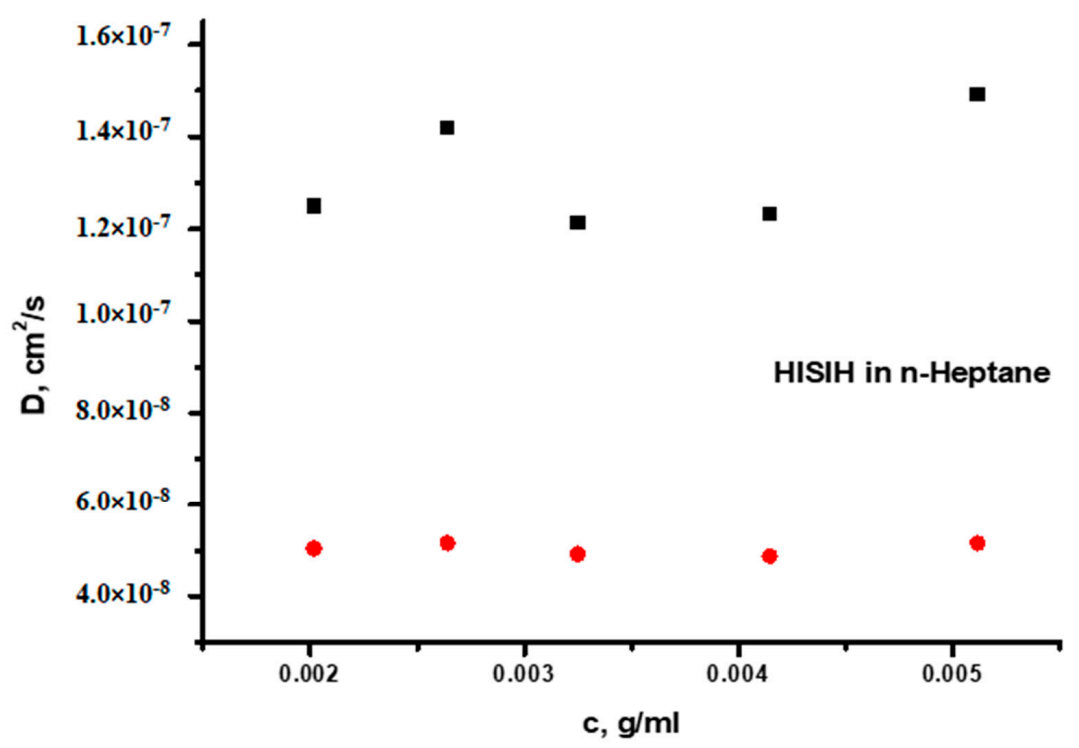

(b)

Figure 5. (a) DLS plots of the two populations of the HISIH pentablock terpolymer in n-dodecane and (b) DLS plots of the two populations of the HISIH pentablock terpolymer in n-heptane.

3.4. Micellization Behavior of PS(PHIC) ${ }_{2}$ Miktoarm Star Copolymers and PS-b-(PI-g-PHIC) Block Graft Terpolymer in n-Heptane

The PS(PHIC $)_{2}$ miktoarm star copolymers having one PS and two PHIC arms and the PS-b-(PI-g-PHIC) block graft terpolymer were prepared by a combination of coordination and anionic polymerization techniques [49]. The PS arms of the stars and the PS-b-PI backbone of the block-graft terpolymer were synthesized by anionic polymerization, whereas the PHIC chains were synthesized by coordination polymerization. The stars are differentiated by the numbers indicating the sample's 
molecular weight (in KDa), the \% wt content in PS and the \% wt content in PHIC. Their molecular characteristics along with their micellar data by LALLS and DLS are given in Table 7, whereas the corresponding plots are provided in Figures 6 and 7. The very low, even negative, $A_{2}$ values for all samples by LALLS clearly indicate the reduced interactions between the polymers and the selective solvent. The degrees of association are unexpectedly high compared with the linear block copolymers having similar compositions and molecular weights. This is an indication that the specific macromolecular architecture promotes s strong intermicellar association, leading to the formation of clusters. It is evident from the LALLS plots that, upon increasing the concentration, there is a gradual increase in the molecular weight and that, only at relatively high concentrations, there is a plateau indicating that equilibrium is finally reached. The molecular weights, included in Table 7, reflect the results obtained from the higher concentration regime when equilibrium between micelles and clusters has been established. The block-graft terpolymer showed a very low degree of association due to both the low PS content and the specific complex macromolecular architecture, which prevents the organization of large multimolecular micelles.

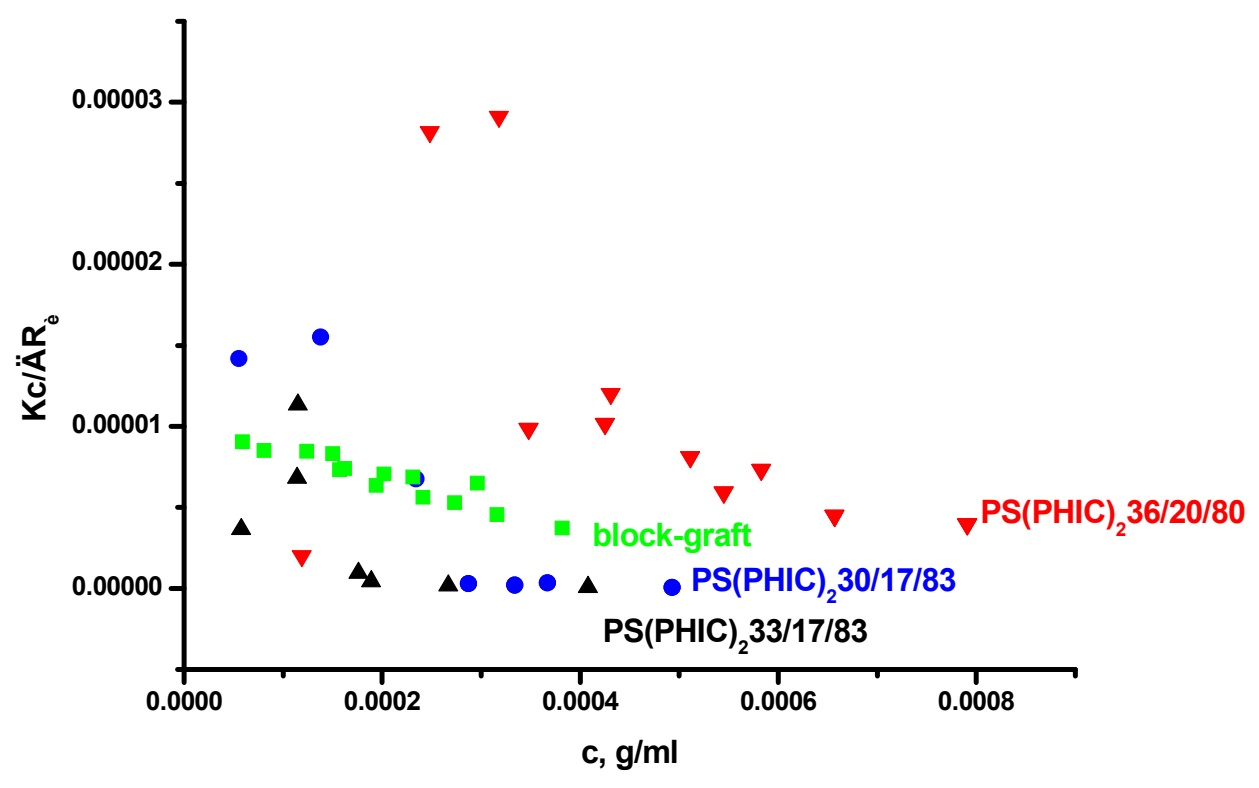

Figure 6. LALLS plots of the miktoarm star and the block-graft copolymers in n-heptane.

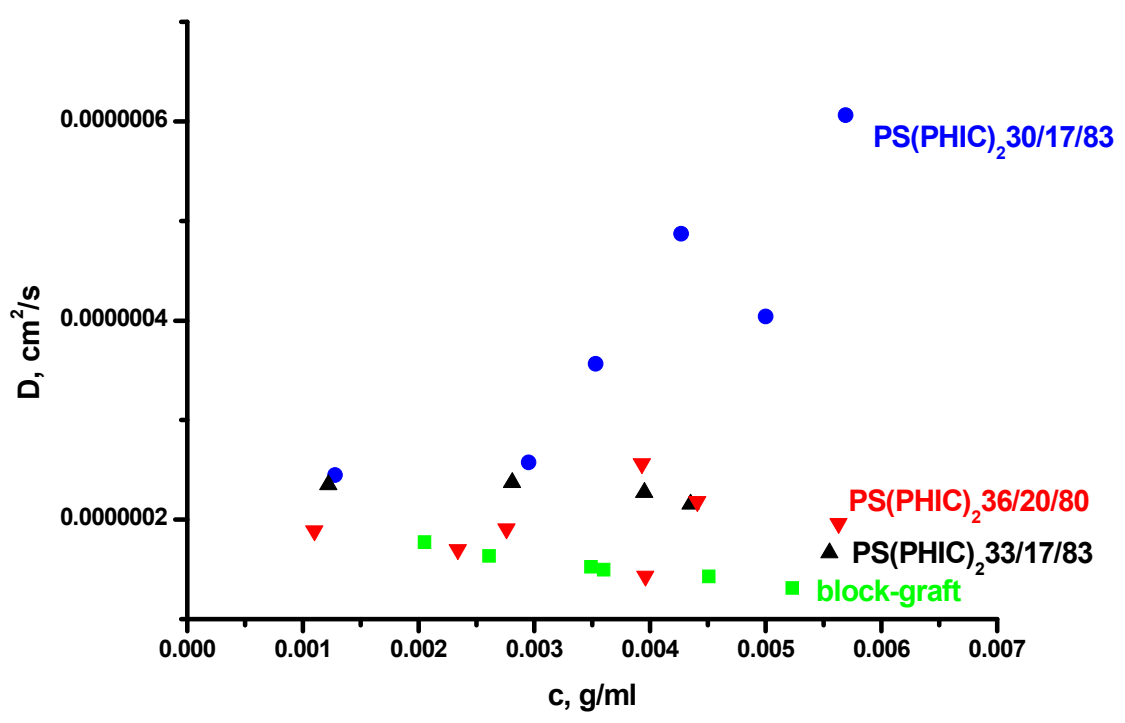

Figure 7. DLS plots of the miktoarm star and the block-graft copolymers in n-heptane. 
Table 7. Molecular characteristics of the PS(PHIC) ${ }_{2}$ miktoarm star copolymers and the PS-b-(PI-g-PHIC)block graft terpolymer and their micellar characteristics in n-heptane.

\begin{tabular}{|c|c|c|c|c|c|c|c|c|c|c|c|}
\hline \multirow[b]{2}{*}{ Sample } & \multirow{2}{*}{$\begin{array}{l}M_{w} \times \\
10^{-3} \mathbf{a}\end{array}$} & \multirow[b]{2}{*}{$\bigoplus^{\mathbf{b}}$} & \multirow[b]{2}{*}{$\% S / H / I, w^{c}$} & \multirow{2}{*}{$\begin{array}{l}A_{2}{ }^{a} \times \\
10^{-3} \mathrm{a}\end{array}$} & \multirow[b]{2}{*}{$\begin{array}{c}\left(\mathrm{M}_{\mathrm{w}} \times\right. \\
\left.10^{-3}\right)_{\text {mic }}\end{array}$} & \multirow[b]{2}{*}{$\mathbf{N}_{\mathbf{w}}$} & \multicolumn{2}{|c|}{ THF } & \multicolumn{3}{|c|}{ n-heptane } \\
\hline & & & & & & & $\begin{array}{c}\mathrm{D}^{\mathrm{d}} \mathrm{cm}^{2} / \mathrm{s} \\
\times 10^{7}\end{array}$ & $\underset{n m}{\mathrm{R}_{\mathrm{h}}{ }^{\mathrm{d}}}$ & $\begin{array}{c}\mathrm{D}^{\mathrm{e}} \mathrm{cm}^{2} / \mathrm{s}^{\mathrm{d}} \\
\times 10^{7}\end{array}$ & $\begin{array}{c}\mathrm{R}_{\mathrm{h} 1} \mathrm{e} \\
\mathrm{nm}\end{array}$ & $\begin{array}{c}\mathrm{R}_{\mathrm{h} 2} \mathrm{e} \\
\mathrm{nm}\end{array}$ \\
\hline $\mathrm{PS}(\mathrm{PHIC})_{2} 30 / 17 / 83$ & 29.7 & 1.18 & $17.0 / 83.0 / 0$ & 0.1 & 5000 & 168 & 5.74 & 8.3 & 2.53 & $\begin{array}{c}21.6 \\
(86.0 \%)\end{array}$ & $\begin{array}{l}144.0 \\
(14 \%)\end{array}$ \\
\hline $\mathrm{PS}(\mathrm{PHIC})_{2} 33 / 17 / 83$ & 32.9 & 1.13 & $17.1 / 82.9 / 0$ & -1.5 & 1000 & 30.4 & 2.65 & 7.8 & 2.68 & $\begin{array}{c}20.4 \\
(90.5 \%)\end{array}$ & $\begin{array}{c}400.9 \\
(9.5 \%)\end{array}$ \\
\hline $\mathrm{PS}(\mathrm{PHIC})_{2} 36 / 20 / 80$ & 36.4 & 1.13 & $20.4 / 79.6 / 0$ & -1.1 & 333.0 & 9.1 & 3.39 & 14.1 & 1.75 & $\begin{array}{c}31.1 \\
(75.0 \%)\end{array}$ & $\begin{array}{c}62.7 \\
(25.0 \%)\end{array}$ \\
\hline PS-b-(PI-g-PHIC) & 91.6 & 1.33 & $14.0 / 82.0 / 4.0$ & -0.80 & 103.0 & 1.1 & 3.99 & 11.9 & 2.00 & 27.2 & - \\
\hline
\end{tabular}

${ }^{\text {a }}$ By LALLS, ${ }^{\mathrm{b}}$ by SEC in THF, ${ }^{\mathrm{c}}$ by ${ }^{1} \mathrm{H}$ NMR in $\mathrm{CDCl}_{3}$ at $25^{\circ} \mathrm{C},{ }^{\text {d }}$ by DLS in THF and ${ }^{\mathrm{e}}$ by DLS in n-heptane and CONTIN analysis. 
The DLS measurements and the CONTIN analysis confirmed the hypothesis which was proposed by the LALLS data. Bimodal distributions were found in n-heptane in the case of the miktoarm star copolymers. Taking into account the DLS data in the common good solvent THF, it can be concluded that the major peak is attributed to small spherical and rather monodisperse micelles whereas the minority peak is attributed to the formation of clusters, which are not spherical and rather loose. The formation of clusters is due to the higher solution concentrations that are employed in order to achieve stable micellar structures. Upon increasing the concentration, there is sufficient space for intermicellar interactions, leading, to a small extent, to the formation of clusters. This behaviour is not observed in the case of the block-graft copolymer due to mainly the steric constraints imposed by the macromolecular architecture.

\subsection{AFM Analysis}

To implement the conclusions drawn by static and dynamic light scattering measurements, AFM images were recorded. Characteristic images for the structures obtained by the SH7.5/9/91 and SH14/18/82 copolymers are given in Figure 8a,b, respectively. Mainly spherical compact micellar structures are observed in Figure 8a, and only a few isolated clusters can be traced in agreement with the conclusion drawn by DLS. The same picture is obvious in the case of the self-assemblies from the sample SH14/18/82. However, the spherical micellar structures are larger in this case and more extended clustering effects, through intermicellar interactions, are visible.

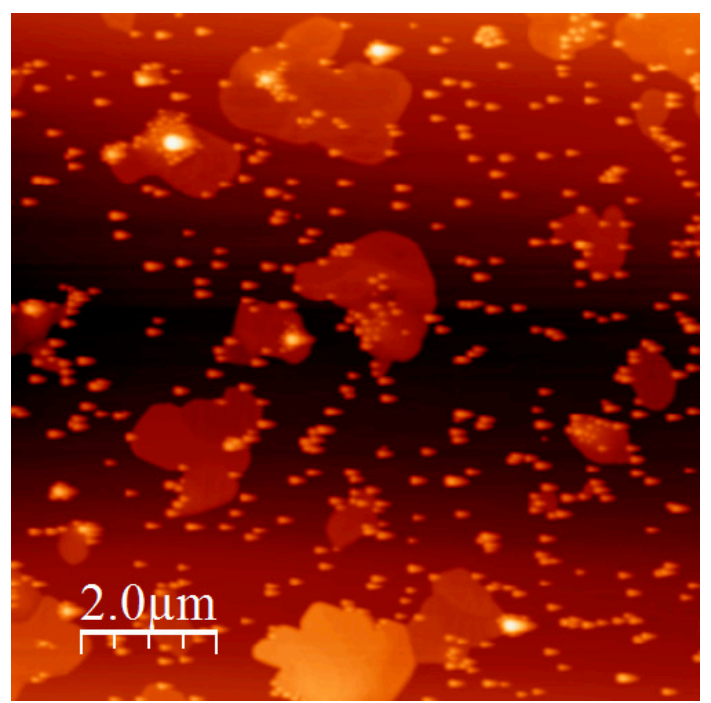

(a)

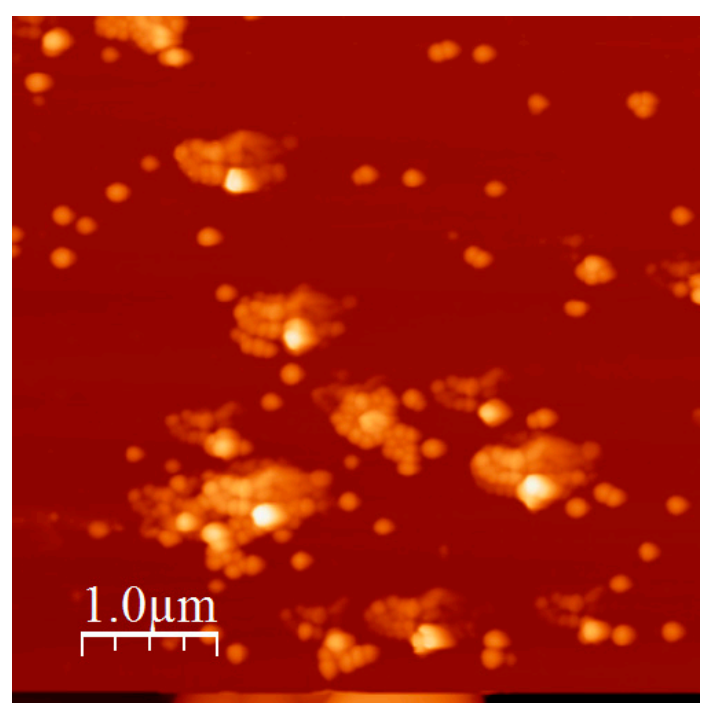

(b)

Figure 8. (a) Atomic force microscopy (AFM) height image of SH7.5/9/91 and (b) AFM height image of SH14/18/82.

Spherical, relatively monodisperse, micelles are obtained in the case of the HSH102/46/54 sample, as shown in Figure 9a confirming the DLS data. Using a more concentrated solution of sample HSH187/41/59 in n-heptane, a similar picture was observed (Figure 9b). However, in this case, a small tendency for clustering is obvious. This is also facilitated by the rapid evaporation of the solvent in the spin coater in order to prepare the film for AFM observation. More interesting results were obtained in the case of the HIH triblock copolymer in n-dodecane. Small spherical structures are obtained from relatively dilute micellar solutions (Figure 10a). These are mainly unimolecular micelles constructed through the formation of loops from the end PHIC blocks. A limited number of intermicellar associates are observed under these experimental conditions. The situation is different using a higher initial micellar concentration, as shown in Figure 10b. The intermicellar associates dominate, leading to the appearance of non-spherical elongated structures. 


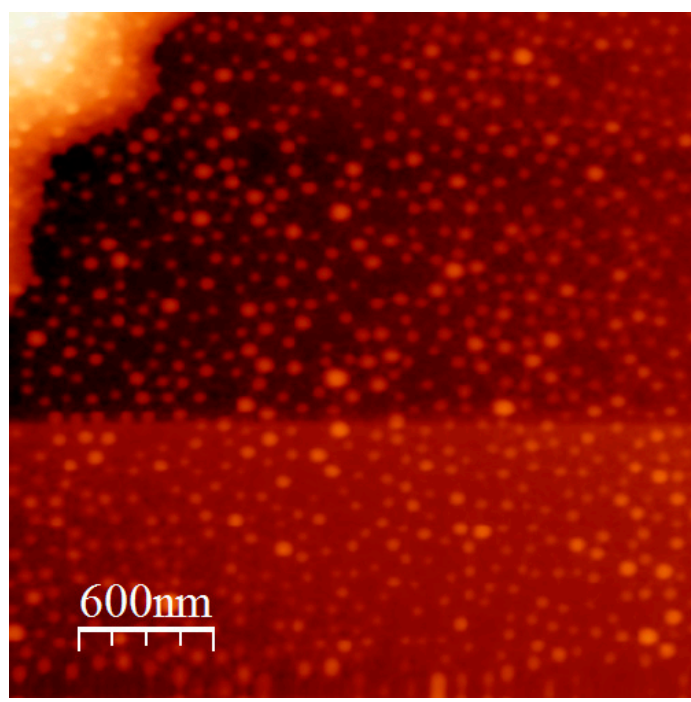

(a)

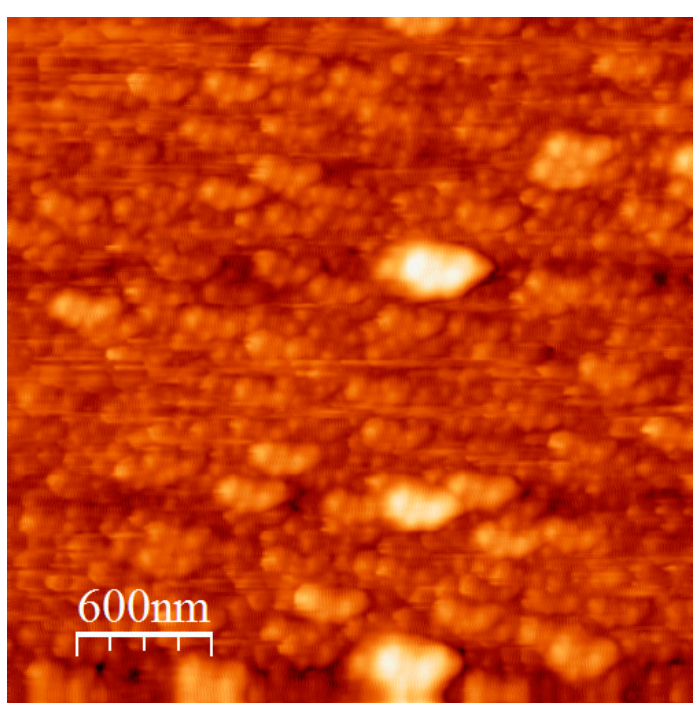

(b)

Figure 9. (a) AFM height image of HSH102/46/54 and (b) AFM height image of HSH187/41/59.

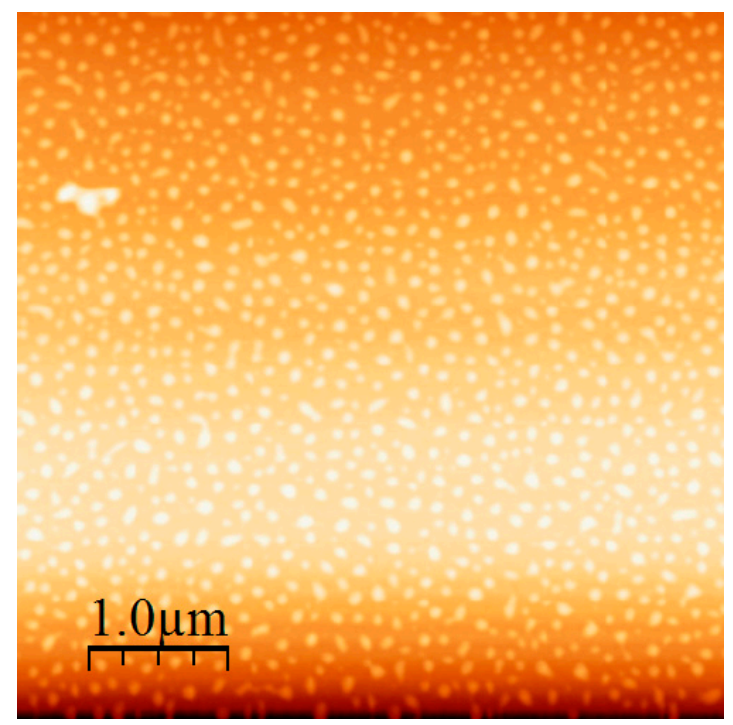

(a)

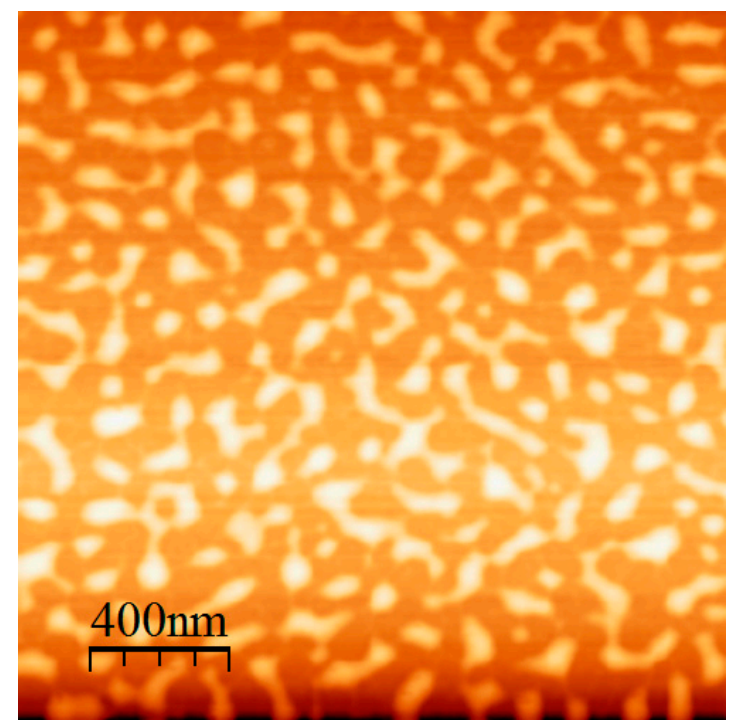

(b)

Figure 10. (a) AFM height image of $\mathrm{HIH}, \mathrm{c}=4 \times 10^{-4} \mathrm{~g} / \mathrm{mL}$, and (b) AFM height image of $\mathrm{HIH}$, $\mathrm{c}=1 \times 10^{-3} \mathrm{~g} / \mathrm{mL}$.

Another interesting result was obtained from the HSISH pentablock terpolymer micelles in n-heptane, as shown in Figure 11a,b. DLS measurements and the CONTIN analysis revealed the existence of equilibrium between spherical micelles and intermicellar associates. AFM images confirm that the initially formed spherical micelles are subjected to intermicellar fusion, leading to the formation of rather well-defined and extended networks. A similar behaviour was observed using core cross-linked micelles [78,79]. The initially formed spherical micelles were gradually transformed to cylindrical structures upon increasing to core component under the influence of external stimuli. Reversible morphological transitions from spherical to cylindrical micelles have been also observed upon changing the temperature [80]. An extremely similar behaviour was also observed when spherical micelles from block copolymers of PHIC with poly(2-vinyl pyridine), P2VP, formed in $\mathrm{CHCl}_{3}$ were subject to intermicellar fusion upon addition of a small amount of THF, which is a common good solvent for both blocks [66]. The result was the appearance of cylindrical micellar networks. In our 
case, similar phenomena are observed with the formation of an almost well-defined nanostructured micellar network. This result could be attributed to the macromolecular architecture, since the middle PI and the outer PHIC blocks are soluble in n-heptane and have to form the micellar corona, whereas the insoluble PS blocks, forming the micellar core, are the intermediate blocks. This architectural frustration leads to strong intermicellar interaction and finally to this characteristic network formation.

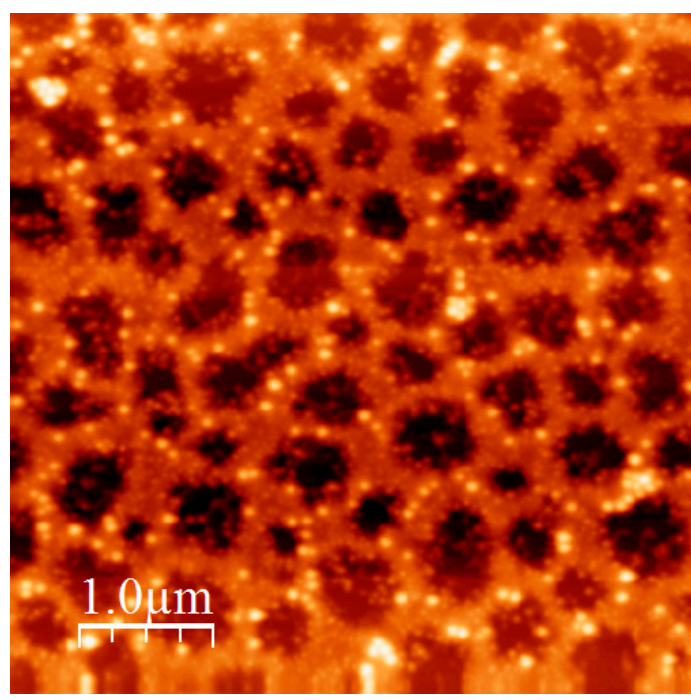

(a)

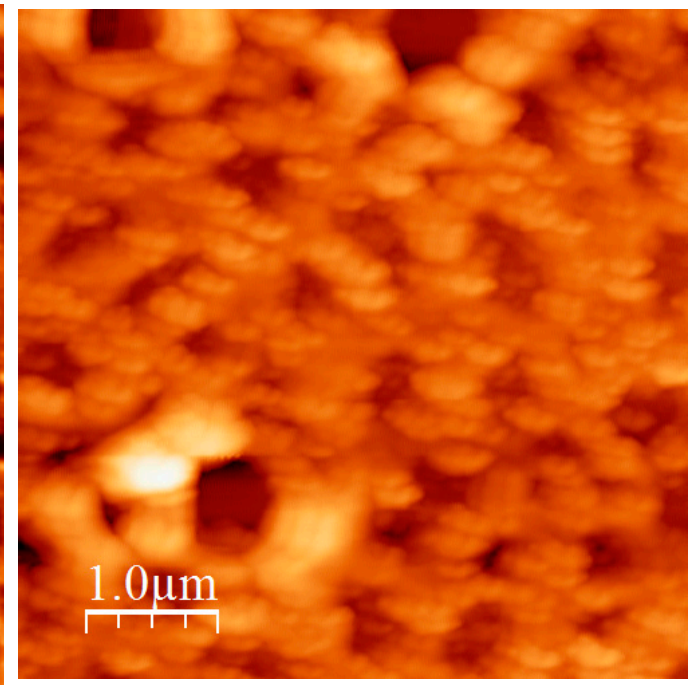

(b)

Figure 11. (a) AFM height image of HISIH and (b) AFM phase image of HISIH.

A characteristic AFM image from the miktoarm star PS(PHIC) $236 / 20 / 80$ is given in Figure 12, whereas a characteristic AFM image from the block-graft copolymer is given in Figure 13. The coexistence of small spherical micelles along with clusters is confirmed by AFM. The clusters are elongated and thus can be considered as small cylinders. This behaviour can be explained by an antiparallel arrangement of the star structures, which brings in close vicinity the insoluble PS blocks surrounded by the soluble PHIC chains (Figure 14). In the case of the block-graft copolymer, the DLS data were verified. Relatively uniform spherical micelles without clustering effects are obtained.

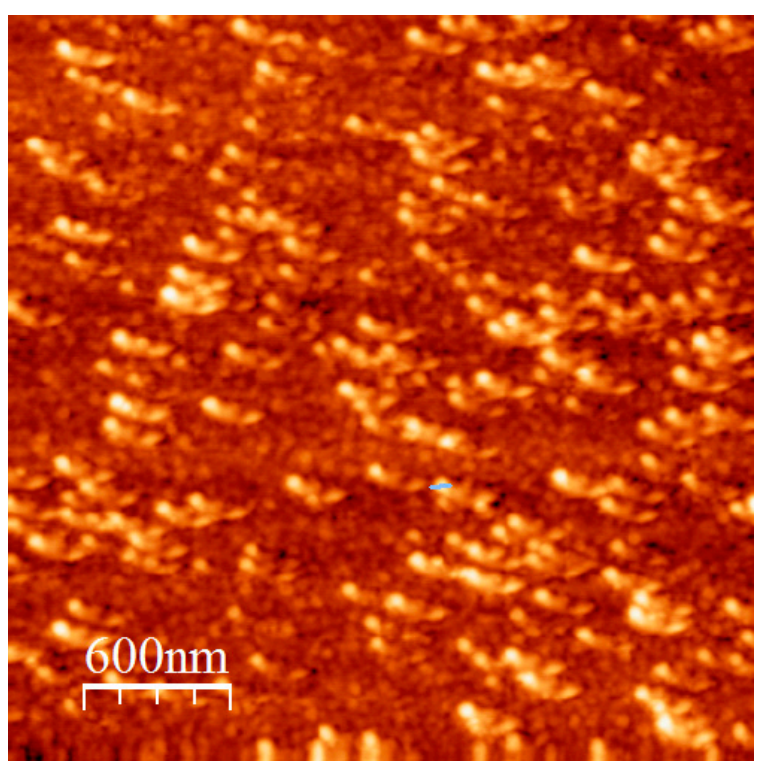

Figure 12. AFM height image of the $\mathrm{PS}(\mathrm{PHIC})_{2} 36 / 20 / 80$. 


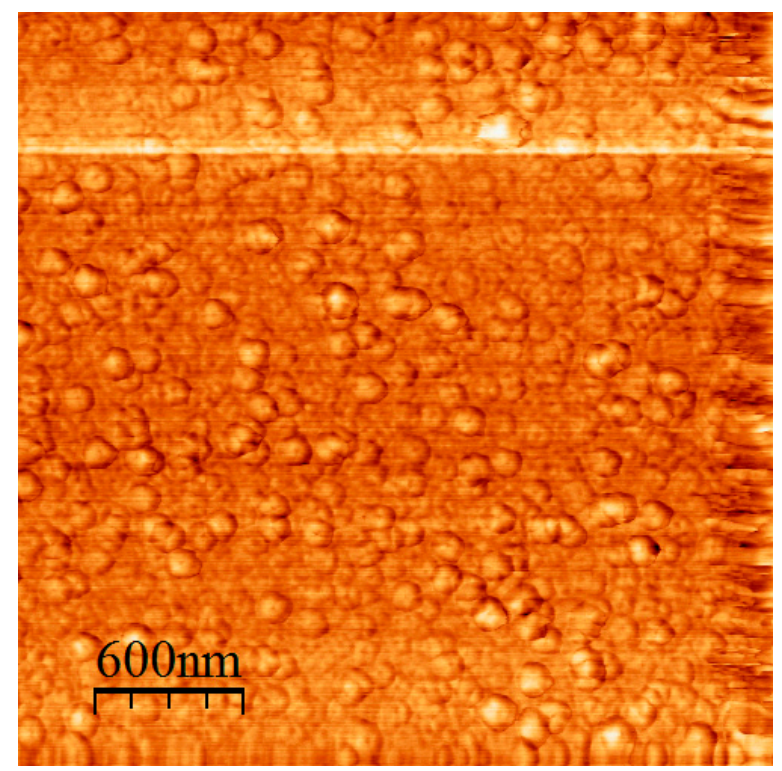

Figure 13. AFM height image of the block-graft copolymer.

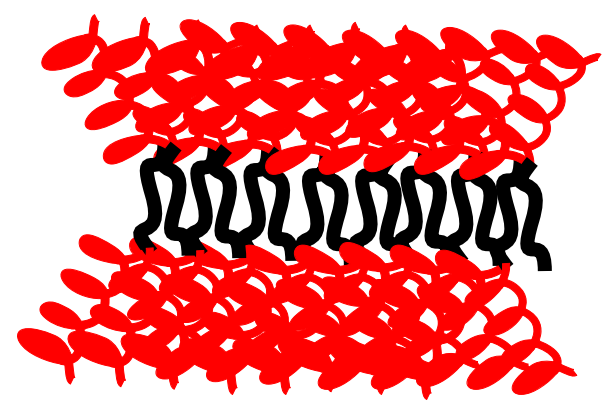

Figure 14. Schematic illustration of the cylindrical aggregates from the interaction of the initially formed spherical micelles.

\section{Conclusions}

The micellization behaviour of various macromolecular architectures, involving diblock and triblock copolymers, pentablock terpolymers, miktoarm star copolymers and block-graft terpolymers, based on poly(hexyl isocyanate), PHIC, was studied in this work. n-Heptane, which is selective for the PHIC or polyisoprene (PI) chains, and n-dodecane, which is selective for the PI chains, were employed. The diblock copolymers form spherical micelles in equilibrium with clusters. The low PS content micelles behave as star-like structures, whereas the high PS content are actually crew-cut micelles. The HSH triblock copolymers form spherical, uniform and thermally stable micelles in n-heptane. The HIH micelles adopt a closed loop conformation in dilution solutions. However, upon increasing the concentration, intermicellar aggregates are formed, leading to elongated cylindrical-type structures. Clustering phenomena were obvious in the case of the pentablock terpolymers in both selective solvents. Of special interest is the HSISH terpolymer in n-heptane which formed an extended network from the intermicellar fusion of spherical micelles. The PS(PHIC $)_{2}$ miktoarm star copolymers form spherical micelles in equilibrium with clusters, which appear to be linear arrangements of the spherical micelles. Finally, the block-graft terpolymer forms mainly unimolecular micelles. It is obvious that the manipulation of the macromolecular architecture leads to a complex micellar behaviour in selective solvents. 
Supplementary Materials: The following are available online at http://www.mdpi.com/2073-4360/12/8/1678/s1, Figure S1: LALLS plot for the sample SH187/92/8; Figure S2: LALLS plot for the sample SH121/90/10; Figure S3: DLS plot for sample SH187/92/8; Figure S4: DLS plot for sample SH14/18/82; Figure S5: DLS plot for sample HIH; Figure S6: Huggins $(\cdot)$ and Kraemer $(\bullet)$ plots for sample SHS102/46/54; Figure S7: Huggins $(\cdot)$ and Kraemer $(\bullet)$ plots for sample SHS187/41/59; Figure S8: AFM height image for sample PS(PHIC) ${ }_{2} 36 / 20 / 80$.

Author Contributions: M.P. was responsible for this work and the design of the experiments. A.V. and M.E. studied the micellization properties of the triblock copolymers and the pentablock terpolymers. G.Z. and A.T. studied the micellization properties of the diblock copolymers. A.T. also studied the micellization behaviour of the miktoarm stars along with the block-graft terpolymer. All authors have read and agreed to the published version of the manuscript.

Funding: The authors acknowledge the financial support of this project from the Special Accounts for Research of the National and Kapodistrian University of Athens.

Conflicts of Interest: The authors declare no conflict of interest.

\section{References}

1. Hadjichristidis, N.; Pispas, S.; Floudas, G.A. Block copolymers. In Synthetic Strategies, Physical Properties and Applications; J. Wiley \& Sons: Hoboken, NJ, USA, 2003.

2. Hamley, I.W. The Physics of Block Copolymers; Oxford University Press: Oxford, UK, 1998.

3. Hadjichristidis, N.; Pitsikalis, M.; Iatrou, H. Synthesis of block copolymers. Adv. Polym. Sci. 2005, 189, 11-24.

4. Theodosopoulos, G.; Pitsikalis, M. Block Copolymers: Recent Synthetic Routes and Developments. In Anionic Polymerization: Principles, Practice, Strength, Consequences and Applications; Hadjichristidis, N., Hirao, A., Eds.; Springer: Tokyo, Japan, 2015; pp. 5416-5423.

5. Abetz, V.; Simon, P.F.W. Phase behaviour and morphologies of block copolymers. Adv. Polym. Sci. 2005, 189, 125-212.

6. Bates, F.M.; Fredrickson, G.H. Block copolymer thermodynamics-theory and experiment. Ann. Rev. Phys. Chem. 1990, 41, 525-557. [CrossRef] [PubMed]

7. Gohy, J.-F. Block copolymer micelles. Adv. Polym. Sci. 2005, 190, 65-136.

8. Riess, G. Micellization of block copolymers. Prog. Polym. Sci. 2003, 28, 1107-1170. [CrossRef]

9. Rodrígeuz-Hernádez, J.; Chécot, F.; Gnanou, Y.; Lecommandoux, S. Toward 'smart' nano-objects by self-assembly of block copolymers in solution. Prog. Polym. Sci. 2005, 30, 691-724. [CrossRef]

10. Kwon, G.S.; Okano, T. Polymeric micelles as new drug carriers. Adv. Drug Deliv. Rev. 1996, 21, $107-116$. [CrossRef]

11. Trubetskoy, V.S. Polymeric micelles as carriers of diagnostic agents. Adv. Drug Deliv. Rev. 1999, 37, 81-88. [CrossRef]

12. Gerst, M.; Schuch, H.; Urban, D. ACS Symposium Series; Glass, J.E., Ed.; ACS Publications: Washington, DC, USA, 2000; Volume 765, pp. 37-51.

13. Riess, G.; Hurtrez, G.; Bahadur, P. Block Copolymers, Encyclopedia Polymer Science and Engineering; Wiley: New York, NY, USA, 1985; Volume 2, pp. 324-434.

14. Torchilin, V.P. Structure and design of polymeric surfactant-based drug delivery systems. J. Control. Release 2001, 73, 137-172. [CrossRef]

15. Kataoka, K.; Harada, A.; Nagasaki, Y. Block copolymer micelles for drug delivery: Design, characterization and biological significance. Adv. Drug Deliv. Rev. 2001, 47, 113-131. [CrossRef]

16. Kabanov, A.V.; Batrakova, E.V.; Alakhov, V.Y. Pluronic (R) block copolymers as novel polymer therapeutics for drug and gene delivery. J. Control. Release 2002, 82, 189-212. [CrossRef]

17. Kakizawa, Y.; Kataoka, K. Block copolymer micelles for delivery of gene and related compounds. Adv. Drug Deliv. Rev. 2002, 54, 203-222. [CrossRef]

18. Bronstein, L.M.; Sidorov, S.N.; Valetsky, P.M.; Hartmann, J.; Coelfen, H.; Antonietti, M. Induced micellization by interaction of poly(2-vinylpyridine)-block-poly(ethylene oxide) with metal compounds. Micelle characteristics and metal nanoparticle formation. Langmuir 1999, 15, 6256-6262. [CrossRef]

19. Sidorov, S.N.; Bronstein, L.M.; Valetsky, P.M.; Hartmann, J.; Coelfen, H.; Schnablegger, H.; Antonietti, M. Stabilization of metal nanoparticles in aqueous medium by poly(ethylene oxide)-poly(ethylene imine) block copolymers. J. Colloid Interface Sci. 1999, 212, 197-211. [CrossRef] [PubMed] 
20. Munch, M.R.; Gast, A.P. Kinetics of block copolymer adsorption on dielectric surfaces from a selective solvent. Macromolecules 1990, 23, 2313-2320. [CrossRef]

21. Breulmann, M.; Förster, S.; Antonietti, M. Mesoscopic surface patterns formed by block copolymer micelles. Macromol. Chem. Phys. 2000, 201, 204-211. [CrossRef]

22. Cao, T.; Yin, W.; Armstrong, J.L.; Webber, S.E. Adsorption of photoactive amphiphilic polymers onto hydrophobic polymer films polystyrene-b-poly(2-vinylnaphthalene)-b-poly(methacrylic acid). Langmuir 1994, 10, 1841-1847. [CrossRef]

23. Spatz, J.P.; Sheiko, S.; Möller, M. Ion stabilized block copolymer micelles film formation and inter micellar interaction. Macromolecules 1996, 29, 3220-3226. [CrossRef]

24. Hong, S.C.; Rief, U.; Kristen, M.O. Ethylene (co) Polymerization with metallocene catalysts encapsulated in gel-type poly(styrene-co-divinylbenzene) beads. Macromol. Rapid Commun. 2001, 22, 1447-1454. [CrossRef]

25. Yu-Su, S.Y.; Thomas, D.R.; Alford, J.E.; LaRue, I.; Pitsikalis, M.; Hadjichristidis, N.; DeSimone, J.M.; Dobrynin, A.V.; Sheiko, S.S. Molding copolymer micelles: A framework for molding of discrete objects on surfaces. Langmuir 2008, 24, 12671-12679. [CrossRef]

26. Spatz, J.P.; Mössmer, S.; Hartmann, C.; Möller, M. Ordered deposition of inorganic clusters from micellar block copolymer films. Langmuir 2000, 16, 407-415. [CrossRef]

27. Lazzari, M.; Scalarone, D.; Hoppe, C.E.; Vazquez-Vazquez, C.; Lòpez-Quintela, M.A. Tunable polyacrylonitrilebased micellar aggregates as a potential tool for the fabrication of carbon nanofibers. Chem. Mater. 2007, 19, 5818-5820.

28. Pitsikalis, M.; Pispas, S.; Mays, J.W.; Hadjichristidis, N. Nonlinear block copolymer architectures. Adv. Polym. Sci. 1998, 135, 1-137.

29. Hadjichristidis, N.; Iatrou, H.; Pitsikalis, M.; Mays, J.W. Macromolecular architectures by living and controlled/living polymerizations. Progr. Polym. Sci. 2006, 31, 1068-1132. [CrossRef]

30. Hadjichristidis, N.; Pitsikalis, M.; Iatrou, H.; Driva, P.; Sakellariou, G.; Chatzichristidi, M. Polymers with star-related structures: Synthesis, properties and applications. Polym. Sci. Compr. Ref. 2012, 6, $29-111$.

31. Hadjichristidis, N.; Pispas, S.; Iatrou, H.; Pitsikalis, M. Linking chemistry and anionic polymerization. Curr. Org. Chem. 2002, 6, 155-176. [CrossRef]

32. Hadjichristidis, N.; Pitsikalis, M.; Iatrou, H.; Pispas, S. The strength of the macromonomer strategy for complex macromolecular architecture: Molecular characterization, properties and applications of polymacromonomers. Macromol. Rapid Commun. 2003, 24, 979-1013. [CrossRef]

33. Hadjichristidis, N.; Iatrou, H.; Pitsikalis, M.; Pispas, S.; Avgeropoulos, A. Linear and non-linear triblock terpolymers. Synthesis, self-assembly in selective solvents and in bulk. Prog. Polym. Sci. 2005, 30, 725-782. [CrossRef]

34. Zamurovic, M.; Christodoulou, S.; Vazaios, A.; Iatrou, E.; Pitsikalis, M.; Hadjichristidis, N. Micellization behaviour of complex comb-like block copolymer architectures. Macromolecules 2007, 40, 5835-5849. [CrossRef]

35. Tsiamantas, C.; Psarros, C.; Mays, J.W.; Pitsikalis, M. Micellization behavior of model asymmetric miktoarm star copolymers of the AA'B type, where A is polyisoprene and B is polystyrene. Polym. J. 2013, 45, 1216-1223. [CrossRef]

36. Minatti, E.; Borsali, R.; Schappacher, M.; Deffieux, A.; Lazzaroni, R. Micellar morphological changes promoted by cyclization of ps-b-pi copolymer: DLS and AFM experiments. Macromolecules 2003, 36, 4125-4133. [CrossRef]

37. Yun, J.P.; Faust, R.; Szilagyi, L.S.; Keki, S.; Zsuga, M. Effect of architecture on the micellar properties of amphiphilic block copolymers: Comparison of ab linear diblock, A1A2B, and A2B heteroarm star block copolymers. Macromolecules 2003, 36, 1717-1723. [CrossRef]

38. Pitsikalis, M.; Woodward, J.; Mays, J.W.; Hadjichristidis, N. Micellization of model graft copolymers in dilute solution. Macromolecules 1997, 30, 5384-5389. [CrossRef]

39. Wu, J.; Pearce, E.M.; Kwei, T.K.; Lefebvre, A.A.; Balsara, N.P. Micelle formation of a rod-coil diblock copolymer in a solvent selective for the rod block. Macromolecules 2002, 35, 1791-1796. [CrossRef]

40. Jenekhe, S.A.; Chen, X.L. Self-assembled aggregates of rod-coil block copolymers and their solubilization and encapsulation of fullerenes. Science 1998, 279, 1903-1907. [CrossRef]

41. Cornelisen, J.J.L.M.; Fischer, M.; Somerdijk, N.A.J.M.; Nolte, R.J.M. Helical superstructures from charged poly(styrene)-poly(isocyanodipeptide) block copolymers. Science 1998, 280, 1427-1430. [CrossRef] 
42. Radzilowski, L.H.; Stupp, S.I. Nanophase separation in monodisperse rod coil diblock polymers. Macromolecules 1994, 27, 7747-7753. [CrossRef]

43. Mayer, S.; Zentel, R. Chiral polyisocyanates, a special class of helical polymers. Progr. Polym. Sci. 2001, 26, 1973-2013. [CrossRef]

44. Zorba, G.; Vazaios, A.; Pitsikalis, M.; Hadjichristidis, N. Anionic polymerization of n-hexyl isocyanate with monofunctional initiators. Synthesis of well-defined diblock copolymers with styrene and isoprene. J. Polym. Sci. Part A Polym. Chem. 2005, 43, 3533-3542. [CrossRef]

45. Bilalis, P.; Zorba, G.; Pitsikalis, M.; Hadjichristidis, N. Synthesis of poly(n-hexyl isocyanate-b-N-vinylpyrrolidone) block copolymers by the combination of anionic and nitroxide-mediated radical polymerizations: Micellization properties in aqueous solutions. J. Polym. Sci. Part A Polym. Chem. 2006, 44, 5719-5728. [CrossRef]

46. Mourmouris, S.; Kostakis, K.; Pitsikalis, M.; Hadjichristidis, N. Polymerization of n-hexyl isocyanate with $\mathrm{CpTiCl}_{2}(\mathrm{OR})(\mathrm{R}=$ functional group or macromolecular chain): A route to functionalized and block copolymers and terpolymers of n-hexyl isocyanate. J. Polym. Sci. Part A Polym. Chem. 2005, 43, 6503-6514. [CrossRef]

47. Vazaios, A.; Pitsikalis, M.; Hadjichristidis, N. Triblock copolymers and pentablock terpolymers of n-hexyl isocyanate with styrene and isoprene: Synthesis, characterization, thermal properties. J. Polym. Sci. Part A Polym. Chem. 2003, 41, 3094-3102. [CrossRef]

48. Zorba, G.; Pitsikalis, M.; Hadjichristidis, N. Novel well-defined star homopolymer and star block copolymers of poly(n-hexyl isocyanate) by anionic polymerization. J. Polym. Sci. Part A Polym. Chem. 2007, 45, 2387-2399. [CrossRef]

49. Touris, A.; Kostakis, K.; Mourmouris, S.; Kotzabasakis, V.; Pitsikalis, M.; Hadjichristidis, N. Complex macromolecular architectures based on n-hexyl isocyanate and $\varepsilon$-caprolactone using titanium-mediated coordination polymerization. Macromolecules 2008, 41, 2426-2438. [CrossRef]

50. Priftis, D.; Petzetakis, N.; Sakellariou, G.; Pitsikalis, M.; Baskaran, D.; Mays, J.W.; Hadjichristidis, N. Surface-initiated titanium-mediated coordination polymerization from catalyst-functionalized single and multiwalled carbon nanotubes. Macromolecules 2009, 42, 3340-3346. [CrossRef]

51. Chae, C.-G.; Seo, H.-B.; Lee, J.-S. Living anionic polymerization of isocyanates. In Anionic Polymerization: Principles, Practice, Strength, Consequences and Applications; Hadjichristidis, N., Hirao, A., Eds.; Springer: Tokyo, Japan, 2015; pp. 339-386.

52. Patten, T.E.; Novak, B.M. Living organotitanium(IV)-catalyzed polymerizations of isocyanates. J. Am. Chem. Soc. 1996, 118, 1906-1916. [CrossRef]

53. Patten, T.E.; Novak, B.M. "Living" titanium(IV) catalyzed coordination polymerizations of isocyanates. J. Am. Chem. Soc. 1991, 113, 5065-5066. [CrossRef]

54. Patten, T.E.; Novak, B.M. Organotitanium(IV) compounds as catalysts for the polymerization of isocyanates: The polymerization of isocyanates with functionalized side chains. Macromolecules 1993, 26, 436-439. [CrossRef]

55. Ishizu, K.; Hatoyama, N.; Uchida, S. Novel synthesis of rod-coil block copolymers by combination of coordination polymerization and ATRP. J. Polym. Sci. Part A Polym. Chem. 2007, 45, 4037-4042. [CrossRef]

56. Choinopoulos, I.; Koinis, S.; Pitsikalis, M. Synthesis and characterization of chiral poly(alkyl isocyanates) by coordination polymerization using a chiral half-titanocene complex. J. Polym. Sci. Part A Polym. Chem. 2015, 53, 2141-2151. [CrossRef]

57. Choinopoulos, I.; Koinis, S.; Pitsikalis, M. Synthesis and characterization of chiral poly(L-lactide-b-hexyl isocyanate) macromonomers with norbornenyl end-groups and their homopolymerization through ring opening metathesis polymerization to afford polymer brushes. J. Polym. Sci. Part A Polym. Chem. 2017, 55, 1102-1112. [CrossRef]

58. Maxein, G.; Mayer, S.; Zentel, R. Structure-property relations in cholesteric networks from chiral polyisocyanates. Macromolecules 1999, 32, 5747-5754. [CrossRef]

59. Itou, T.; Teramoto, A. Isotropic-liquid crystal phase equilibrium in solutions of semiflexible polymers: Poly(hexyl isocyanate). Macromolecules 1988, 21, 2225-2230. [CrossRef]

60. Aharoni, S.M. Rigid backbone polymers. 2. Polyisocyanates and their liquid-crystal behavior. Macromolecules 1979, 12, 94-103. [CrossRef] 
61. Green, M.M.; Gross, R.A.; Crosby, C., III; Schilling, F.C. Macromolecular stereochemistry: The effect of pendant group structure on the axial dimension of polyisocyanates. Macromolecules 1987, 20, 992-999. [CrossRef]

62. Muller, M.; Zentel, R. Dilute-solution chiral optical changes signal the thermally reversible gelation of poly(n-hexyl isocyanate) in hydrocarbon Solvents. Macromolecules 1993, 26, 4723-4725.

63. Maeda, K.; Okamoto, Y. Synthesis and conformation of optically active poly(phenyl isocyanate)s bearing an $((S)-(\alpha$-methylbenzyl)carbamoyl) group. Macromolecules 1998, 31, 1046-1052. [CrossRef]

64. Wu, J.; Pearce, E.M.; Kwei, T.K. A novel rod-coil block copolymer anf its compatible blends. Macromolecules 2001, 34, 1828-1836. [CrossRef]

65. Sakai, N.; Satoh, T.; Kakuchi, T. Rod-like amphiphile of diblock polyisocyanate lleading to cylindrical micelle and spherical vesicle in water. Macromolecules 2014, 47, 1699-1704. [CrossRef]

66. Koh, H.-D.; Changez, M.; Rahman, M.S.; Lee, J.-S. Formation of intermicellar-chained cylindrical micellar networks from an amphiphilic rod-coil block copolymer: Poly(n-hexyl isocyanate)-block-poly(2vinylpyridine). Langmuir 2009, 25, 7188-7192. [CrossRef]

67. Wu, D.; Huang, Y.; Xu, F.; Mai, Y.; Yan, D. Recent advances in the solution self-assembly of amphiphilic "rod-coil" copolymers. J. Polym. Sci. Part A Polym. Chem. 2017, 55, 1459-1477. [CrossRef]

68. Provencher, S.W. CONTIN: A general purpose constrained regularization program for inverting noisy linear algebraic and integral equations. Comput. Phys. Commun. 1982, 27, 229-242. [CrossRef]

69. Halperin, A. Polymeric micelles: A star model. Macromolecules 1987, 20, 2943-2946. [CrossRef]

70. Noolandi, J.; Hong, M.H. Theory of block copolymer micelles in solution. Macromolecules 1983, 16, 1443-1448. [CrossRef]

71. Leibler, L.; Orland, H.; Wheeler, J.C. Theory of critical micelle concentration for solutions of block copolymers. J. Chem. Phys. 1983, 79, 3550-3557. [CrossRef]

72. Nagarajan, R.; Ganesh, K. Block copolymer self-assembly in selective solvents-Theory of solubilization in spherical micelles. Macromolecules 1989, 22, 4312-4325. [CrossRef]

73. Kotsis, N.; Siakali-Kioulafa, E.; Pitsikalis, M. Micellization behavior of diblock and triblock copolymers of poly(t-butyl methacrylate) bearing associating short polystyrene end-blocks. Eur. Polym. J. 2008, 44, 2687-2694. [CrossRef]

74. Balsara, N.P.; Tirrell, M.; Lodge, T.P. Micelle formation of BAB triblock copolymers in solvents that preferentially dissolve the A block. Macromolecules 1991, 24, 1975-1986. [CrossRef]

75. Booth, C.; Attwood, D. Effects of block architecture and composition on the association properties of poly(oxyalkylene) copolymers in aqueous solution. Macromol. Rapid Commun. 2000, 21, 501-527. [CrossRef]

76. ten Brinke, G.; Hadziioannou, G. Topological constraints and their influence on the properties of synthetic macromolecular systems. 2. Micelle formation of triblock copolymers. Macromolecules 1987, 20, 486-489. [CrossRef]

77. Tuzar, Z.; Kratochvil, P. Micelles of block and graft copolymers in solution. Surf. Colloid Sci. 1993, 15, 1-83.

78. Zhang, L.; Eisenberg, A. Multiple morphologies and characteristics of "crew-cut" micelle-like aggregates of polystyrene- $b$-poly(acrylic acid) diblock copolymers in aqueous solutions. J. Am. Chem. Soc. 1996, 118, 3168-3181. [CrossRef]

79. Zhang, L.; Eisenberg, A. Multiple morphologies of "crew-cut" aggregates of polystyrene-b-poly(acrylic acid) block copolymers. Science 1995, 268, 1728-1731. [CrossRef]

80. LaRue, I.; Adam, M.; Pitsikalis, M.; Hadjichristidis, N.; Rubinstein, M.; Sheiko, S.S. Reversible morphological transitions of polystyrene-b-polyisoprene micelles. Macromolecules 2006, 39, 309-314. [CrossRef]

(C) 2020 by the authors. Licensee MDPI, Basel, Switzerland. This article is an open access article distributed under the terms and conditions of the Creative Commons Attribution (CC BY) license (http://creativecommons.org/licenses/by/4.0/). 